\title{
Numerical analysis and performance comparison of the same series of composite
}

\section{propellers}

\author{
Y. Hong ${ }^{\mathrm{a}, *}, \quad$ Philip A. Wilson ${ }^{\mathrm{b}}, \quad$ X. D. He $\mathrm{a}^{\mathrm{a}, *}, \quad$ R. G. Wang ${ }^{\mathrm{a}}$
}

${ }^{a}$ Science and Technology on Advanced Composites in Special Environment

Laboratory, Harbin Institute of Technology, Harbin 150080, P.R.China

${ }^{\mathrm{b}}$ Fluid Structure Interactions Research Group, University of Southampton, UK

\begin{abstract}
Composite marine propeller, due to its potential advantage of reduced weight and noise reduction, has increasingly attracted the attention of researchers. In the current work, the performance and efficiency of the $438 \mathrm{x}$ series of composite propellers are studied based on the finite element method (FEM) and the computational fluid dynamics method(CFD). The influence of blade skew angle on the hydro-elastic performance、 cavitation and efficiency of composite marine propeller are discussed. The performance differences are compared between composites series propellers and metal series propellers. According to the performance characteristics of the same series of composite propellers, a fast and effective design method is proposed.
\end{abstract}

\section{Keywords}

composite marine propeller; hydro-elastic performance; cavitation; efficiency

\section{Notation}

[A] The angular velocity matrix

B Linear strain-displacement transformation matrices

$B_{L} \quad$ Nonlinear strain-displacement transformation matrices

*Corresponding author, Tel. +86 45186402323

E-mail address: hongyi@hit.edu.cn(Y. Hong); hehrbhit@163.com(X.D. He) 
D Propeller diameter

$D_{\mathrm{m}} \quad$ Material property matrix

$\left\{F_{h}\right\}$ Generalized fluid force normal to the surface of the blade

$\left\{F_{r}\right\}$ Centrifugal force

G A matrix defined purely in terms of coordinates

J Advance coefficient

$K_{T} \quad$ Thrust coefficient

$K_{Q} \quad$ Torque coefficient

$\left[K_{l}\right]$ Linear stiffness matrix

$\left[K_{0}\right]_{\text {Initial displacement matrix }}$

$\left\lfloor K_{g}\right\rfloor$ Geometric matrix

$\left[K_{r}\right]$ Rotational stiffness matrix

$m$ Outward normal vector

$n \quad$ Propeller rotating velocity

$[N]$ Displacement interpolation matrix

$P_{o} \quad$ Static pressure

$P_{k} \quad$ Vapor pressure

$P \quad$ The total hydrodynamic acting on the blade

$P_{r} \quad$ The hydrodynamic pressure due to rigid-blade rotation

$P_{v} \quad$ The hydrodynamic pressure due to elastic blade deformation

Q Propeller torque

R Propeller radius 
T Propeller thrust

$\{u\} \quad$ Nodal displacement vectors

$V_{A} \quad$ Speed of advance of propeller

Greek alphabet

$\Omega \quad$ Rotating constant angular velocity

$\eta \quad$ Propeller efficiency

$\rho \quad$ Density of water

$\rho_{\mathrm{m}} \quad$ Density of the material of the blade

$\sigma$ Cavitation number

\section{Introduction}

Traditionally metallic propellers are subject to corrosion and cavitation damage, fatigue-induced cracking, and have relatively poor acoustic damping properties that can lead to noise ${ }^{[1]}$. In recent years, the potential benefits of composites play an important role in improving the performance of marine propeller, especially for large size and high performance ships requiring weight loss, vibration and noise reduction. In the literature composite propeller has been shown to a weight of only one-third the weight of conventional Nickel-Aluminum Bronze (NAB), reducing the propeller noise typically by $5 \mathrm{~dB}$, and reducing the fuel consumption by up to $15 \%$ by using the hydro-elasticity to optimize propulsive efficiency ${ }^{[2]}$.

In recent years, a considerable amount of research has been completed on composite marine propellers. $\operatorname{Lin}^{[3-4]}$ et al calculated the stress of a composite blade under the fluid pressure and centrifugal loads using the commercial finite element 
software ABAQUS, and compared with a geometrically identical isotropic metal propeller. The composite blade was composed of multiple layers of braided fiber and a foam-filled core, the fluid pressure and centrifugal loads were considered using PSF-2 program (a software program for analyzing the flow field of a propeller in steady and subcavitating flows). Subsequently, Lee ${ }^{[5-6]}$ et al studied the optimized design method of the composite blade using the genetic algorithm, and completed the corresponding experiment in subsequent study. $\operatorname{Lin}^{[7-8]}$ et al developed a coupled 3-D FEM/VLM (Vortex-lattice Methods) method for analyzing composite propeller in steady flow, the strength and the underwater free vibration of the composite blade were analyzed. At the same time, Young and Motley ${ }^{[9-13]}$ et al presented a coupled FEM/BEM (Boundary Element Method) approach to comprehensively investigate flexible composite propellers in subcavitating and cavitating flows. The hydrodynamic performance and efficiency were improved by utilizing the bend-twist coupling effects of composites. Recently, Paiket ${ }^{[14]}$ et al studied the performance characteristics of three kinds of flexible propellers, and tested and analyzed the tip vortex cavitation and the acoustic noise performances. Herath and Prusty et al ${ }^{[15-17]}$ presented a layup optimization algorithm for composite marine propeller. The off-design propulsive efficiency was improved by using the Finite Element Method combined with Genetic Algorithm (GA). Shenoi et $\mathrm{al}^{[18-20]}$ discussed the manufacturing aspects of composite blades.

Based on the above outstanding research, this paper will further study the hydro-elastic performance、 cavitation and efficiency of the same series of composite 
propellers. For the research of the same series of propellers, especially the same series of metal propellers, has carried out a lot of work in the past. However, there are significant differences in material properties between the metal and the composite, so this is particularly important to study the performances of the same series of composite propellers. For the same series of metal propellers, the designers found that the geometrical features, such as propeller diameter, skew, pitch distribution et al, are the main factors that affect the efficiency and cavitation performance of metal propeller. Therefore, in the design process of full-sized metal propeller, the main task was select proper geometrical parameters, according to the ship type, main engine and working condition, for improving the efficiency and reducing the cavitation. For the same series of composite propellers, due to the elastic characteristic of composites, the designer cannot determine what is the most important factor affecting the performances of the same series of composite propellers. The factor may be the geometric factors, such as propeller diameter, skew, pitch distribution et al. It may be the structural factors, such as material type, lamination scheme et al. In order to realize the fast and effective design of the full-size composite propeller, it is worth to detailed analysis the performance of the same series of composite propellers.

\section{Computation method and Analysis tools}

\subsection{Physical model}

Figure 1 shows geometries of the study object: the $438 \mathrm{x}$ series of skewed propellers. The series propeller comprised four propellers having the skew angles of $0^{\circ}, 36^{\circ}, 72^{\circ}, 108^{\circ}$ at the propeller tip respectively. The propellers both consist of five 
blades and have a diameter of $304.8 \mathrm{~mm}(12 \mathrm{in})$, a expanded area ratio of 0.725 . The detailed geometry parameters can be found in literature ${ }^{[22]}$.

\subsection{Computational model and boundary conditions}

In this paper, the hydro-elastic performances of composite marine propeller are calculated based on the finite element method (FEM) coupled with computational fluid dynamics (CFD). To construct the finite element model in the coupled matrix, we choose a reference blade for composite propeller, as shown in Figure 2. The composite propeller rotating with a constant angular velocity $\Omega$ about a fixed $\mathrm{x}$ axis. the finite element model of the reference blade is constructed by the layered solid elements $^{[23]}$. We define one element in the thickness direction of the blade, and consider per element to be a symmetric graphite-epoxy laminate composed of different orientation plies. The number of plies for per element is different due to the blade thickness is a function of position. Figure 3 shows the finite element model of 438x series of composite propeller generated by the software ANSYS. The model consists of 798 layered solid elements. Table 1 lists the properties of the composite materials used in the model. A symmetric stacking sequence scheme $\left[00_{2} / 45_{2} /-45_{2} \ldots\right]_{\mathrm{s}}$, beginning from the pressure and suction surfaces to the camber surface, is chosen for initial constructing the composite blade. The root of the blade is fixed to simulate the boundary conditions of a real propeller blade.

In the coupled simulation, the fluid is assumed to be viscid and incompressible. With these assumptions, the hydrodynamic characteristics of the composite propeller can be solved by applying the CFD method based on RANS equation. To construct 
the fluid model of composite propeller in the open water, the computational domain is created as one passage surrounding five blades: inlet at $1.5 \mathrm{D}$ upstream, where $\mathrm{D}$ is the propeller diameter; outlet at 3.5D downstream; outer boundary at $1.5 \mathrm{D}$ from the hub axis. The blade and hub are modeled as a solid surface, and the no slip condition is imposed, centered at the coordinate system origin. To ensure that solutions yield sufficient accuracy, the mesh dependency study has been performed. In grid generation, the non-dimensional normal distance of the first cell layer towards wall is maintained at a value $\mathrm{y}+\approx 1$ for the $438 \mathrm{x}$ series of propellers. The realizable SST $\mathrm{k}-\varepsilon$ turbulence model is chosen to solve the three-dimensional steady Reynolds averaged equations ${ }^{[24]}$. The Semi-Implicit Method for Pressure Linked Equations (SIMPLE) algorithm is selected as the pressure velocity coupling method. Boundary conditions are set to simulate the flow around a rotating propeller in the open water. Figure 4 shows the global fluid meshes, Figure 5 shows the detailed fluid mesh on the composite blade.

\subsection{Coupling calculation method}

In order to reduce the computational load, we only consider the coupling calculation of single composite blade. The coupling equation is constructed and expressed as

$$
\left\{\left[K_{l}\right]+\left[K_{0}\right]+\left[K_{g}\right]-\left[K_{r}\right]\right\}\{u\}=\left\{F_{r}\right\}+\left\{F_{h}\right\}
$$

Where $\{u\}$ is the nodal displacement vectors, $\left\{F_{h}\right\}$ is the generalized fluid force normal to the surface of the blade, $\left\{F_{r}\right\}$ is the centrifugal force. $\left[K_{l}\right],\left[K_{0}\right]$, $\left\lfloor K_{g}\right\rfloor$ and $\left[K_{r}\right]$ are the linear stiffness matrix, the initial displacement matrix, the 
geometric matrix and the rotational stiffness matrix, respectively, and can be expressed as

$$
\begin{gathered}
{\left[K_{l}\right]=\int B^{T} D_{\mathrm{m}} B_{L} d V} \\
{\left[K_{0}\right]=\int\left(B^{T} D_{\mathrm{m}} B_{L}+B_{L}^{T} D_{\mathrm{m}} B_{L}+B_{L}{ }^{T} D_{\mathrm{m}} B\right) d V} \\
{\left[K_{g}\right]=\int G^{T}\left[\begin{array}{ll}
\sigma_{x} & \tau_{x y} \\
\tau_{x y} & \sigma_{y}
\end{array}\right] G d V} \\
{\left[K_{r}\right]=\rho_{\mathrm{m}} \int[N]^{T}[A][N] d V}
\end{gathered}
$$

In these equations, $B$ and $B_{L}$ represent linear and nonlinear strain-displacement transformation matrices, respectively. $D_{\mathrm{m}}$ is the material property matrix. $\mathrm{G}$ is a matrix defined purely in terms of coordinates. $[N]$ is the displacement interpolation matrix, $[A]$ is the angular velocity matrix, and $\rho_{\mathrm{m}}$ is the density of the material of the blade. The equation is formed based on a full Lagrange description and solved using the Newton-Raphson method.

At the same time, the forces of the fluid acting on the blades are expressed as

$$
\left\{F_{h}\right\}=\int_{A}[N]^{T} m P d A
$$

in which $d A$ is the interaction boundary between the fluid and structure, and $m$ is its outward normal vector. $[\mathrm{N}]$ is the displacement interpolation matrix, which depends on the element types used in the structural calculation. $P$ is the total hydrodynamic acting on the blade, and it can be decomposed into two parts

$$
P=P_{r}+P_{v}
$$

where $P_{r}$ and $P_{v}$ are the hydrodynamic pressure due to rigid-blade rotation and elastic blade deformation, respectively.

Substituting Eq. (6) and Eq. (7) into Eq. (1), we can obtain the coupling 
equation:

$$
\left\{\left[K_{l}\right]+\left[K_{0}\right]+\left[K_{g}\right]-\left[K_{r}\right]\right\}\{u\}-\int_{A}[N]^{T} m\left\{P_{v}\right\} d A=\left\{F_{r}\right\}+\int_{A}[N]^{T} m\left\{P_{r}\right\} d A
$$

According to the coupling equation, and combined with the above finite element model and fluid model, the hydro-elastic coupling of composite marine propeller can be calculated by using the commercial FEM/CFD software package ANSYS/ANSYS CFX. The hydrodynamic force and structural response are calculated and transferred between the CFD Solver and the FEM Solver. The non-matching meshes can be supported by the CFX GGI technology. The conservative interpolation scheme is used when sending flows (Force), and the profile preserving interpolation scheme is used when sending fluxes (Displacement). The Newton-Raphson numerical procedure is applied to complete the solution of the coupling calculation. In the CFX solver, the convergence values of the momentum residuals are set to 1e-4. In the Ansys solver, the convergence values of the force and displacement are set to 0.001 , the relaxation factor is 0.75 . The whole coupling iteration process is shown in the Figure 6.

\section{Results and Discussions}

\subsection{Validation of coupling method}

Because the 3-D FEM/CFD coupling algorithm has been suitably validated for high skewed composite propeller in authors' previous studies ${ }^{[25]}$, the validity of this method for non-skewed 4381 composite propeller is mainly discussed below.

A convergence calculation is completed for 4381 composite propeller with different grid sizes. A total of 530,700 cells, dividing by mesh size 1 , is used for the open water flow simulation of 4381 composite propeller. Another two meshing 
schemes, dividing by mesh size 2 and mesh size 3 , are used for validation study. Figure 7 and Figure 8 show the thrust coefficient $K_{T}\left(K_{T}=T / \rho n^{2} D^{4}\right)$ and the torque coefficient $K_{Q}\left(K_{Q}=Q / \rho n^{2} D^{5}\right)$ with different grid sizes in steady flow, respectively. It is clear that the open water hydrodynamic load coefficients are convergent for different grid sizes, and we can conclude that the 3-D FEM/CFD method is validated also suitable for the hydro-elastic calculation of the non-skewed composite propeller.

\subsection{The hydrodynamic performance}

According to the chosen material and stacking scheme, the hydrodynamic performances of the series of composite propeller in open water can be calculated by the coupled FEM/CFD method. These calculated results are compared with the calculated and measured results ${ }^{[26]}$ of the series of metal propeller. The rotating speed $n$ of all propellers during the simulation is set to $7.8 \mathrm{rps}$, which is consistent with the rotating speed of the experimental process.

Figure 9-12 display the thrust coefficient $K_{T}$, the torque coefficient $K_{Q}$ and the

efficiency $\eta\left(\eta=\frac{J}{2 \pi} \frac{K_{T}}{K_{Q}}\right)$ for the 4381, 4382, 4383, 4384 composite propellers and metal propellers, respectively. We can see obviously that the calculation results of the metal propeller are basically consistent with the test results, and the errors are controlled within 3\%. The thrust、torque and efficiency of the composite propeller are mostly lower than those of the metal propeller. For the non-skewed 4381 and low-skewed 4382 composite propellers, the reduction in efficiency is mainly reflected in the range of advance coefficient $\mathrm{J}=0.95$ to $\mathrm{J}=1.1$. For the high-skewed 4383 and 
4384 composite propellers, the reduction in efficiency is reflected in the range of advance coefficient $\mathrm{J}=0.5$ to $\mathrm{J}=1.2$. It is important to note that the 4383 composite propeller has the maximum reduction in the efficiency. This phenomenon may be related to the design laying scheme. For the blade shape of the 4383 propeller, the arrangement of the fibers in the laying scheme $\left[02_{2} / 45_{2} /-45_{2} \ldots\right]_{\mathrm{s}}$ provides the smallest contribution to the main direction of the blade, which resulting in a considerable reduction in the thrust and torque and a corresponding reduction in efficiency of 4383 composite propeller.

Figure 13 shows the pressure distributions of the pressure surface and the suction surface of the $438 \mathrm{x}$ series of composite propellers. Figure 14 shows the vorticity contours of a cross section A behind the $438 \mathrm{x}$ series of composite propellers, Figure 15 presents a schematic view of the cross-section A. Figure 16 compares the maximum efficiency of the $438 \mathrm{x}$ series of propellers. It is clear that the value of the maximum efficiency almost is stable for the $438 \mathrm{x}$ series of metal propellers, however, the value of the maximum efficiency has a big change for the $438 \mathrm{x}$ series of composite propellers. Under the same host power, that is, the rotation speed of the blade, this is a significant difference of the thrust characteristics between composite series propellers with metal series propellers.

\subsection{Cavitation}

In order to analyze the differences of the cavitation performance between the same series of composite propellers and metal propellers, we calculated the cavitation number $\sigma\left(\sigma=\frac{2\left(P_{o}-P_{k}\right)}{\rho\left(V_{A}^{2}+(x \pi n D)^{2}\right)}, x=0.7\right)$ of all propellers under the advance 
velocity $V_{A}$ corresponding to the maximum efficiency.

Figure 17 shows the calculation results of the cavitation number at $0.7 \mathrm{R}$ cross section. From the result we can see that the cavitation number of the composite propeller is significantly higher than that of the metal propeller when the maximum efficiency is achieved. It exhibits that the composite propeller has better ability to prevent the occurrence of cavitation than the metal propeller. At the same time, the cavitation number shows a similar tendency with the maximum efficiency. The cavitation numbers of different skewed metal propellers are identical, and the cavitation numbers of different skewed composite propellers are greater difference.

\subsection{The hydro-elastic performance}

The hydro-elastic structural responses of the series of composite propellers in open water are calculated by the coupled FEM/CFD method. Due to there have been a lot of research work on the hydro-elastic structural performances of composite propellers such as strength, stress and displacement, etc. The paper will focus on discussing the hydro-elastic performance differences of the same series of composite propellers. Figure 18 shows the predicted maximum displacement of the $438 \mathrm{x}$ series of composite propellers. We can see that the larger the skew angle, the greater the maximum displacement of the composite propeller. It should be noted that the change of the maximum displacement is not significant for the non-skewed and low-skewed composite propellers in the range of advance coefficient $\mathrm{J}=0.3$ to 1.3 , however, the change is great for the high-skewed composite propellers. In order to more clearly show the deformed geometry of composite series propellers, Figure 19 presents the 
deformation contours of composite propellers at $\mathrm{J}=1.08$. It is clear that the deformations of composite series propellers are concentric annular distribution, and the largest deformation occurs at the tip of the blade. Figure 20 shows the pitch angle changes between the deformed and un-deformed shapes at the blade tip of the $438 \mathrm{x}$ series of composite propellers. It should be noted that the pitch angles of the non-skewed and low-skewed composite propellers increase first and then decrease, however, the pitch angles of the high-skewed composite propellers has been increasing in the full speed range.

Figure 21 compares the maximum principal stress of the $438 \mathrm{x}$ series of composite propellers. The result shows that, in the range of advance coefficient $\mathrm{J}=0.3$ to 1.3 , the changes of the maximum principal stresses of the non-skewed and low-skewed composite propellers are less than that of the high-skewed composite propeller. Table 2 further lists the element number and the number of layers with the maximum principal stress when the advance coefficient $J=1.08$. Figure 22 shows the principal stress contours of the $438 \mathrm{x}$ series of composite propellers at the layer corresponding the maximum principal stress.

\section{Conclusions}

The hydro-elastic phenomena of the $438 \mathrm{x}$ series of composite propeller are investigated using a 3-D FEM/CFD coupling algorithm. The hydrodynamic performances (including thrust coefficient、torque coefficient and efficiency), the cavitation performance and the hydro-elastic structural responses are calculated and compared between the same series of different propellers. The differences of the 
cavitation and efficiency between composites series propeller and metal series propeller are analyzed. Based on these results, the following conclusions can be drawn:

(1) The 3-D FEM/CFD coupling algorithm is validated for the non-skewed composite propeller in open water.(The 3-D FEM/CFD coupling algorithm has been applied and validated suitable for high skewed composite propeller in authors' previous studies ${ }^{[25]}$ )

(2) For the same series of composite propellers, the geometrical and structural factors all have a significant effect on the propeller performances. When we choose the same structural scheme, the maximum efficiency and the corresponding cavitation number are greatly different between the same series of different propellers. This is a significant difference from the characteristics of the same series of metal propellers.

(3) When we choose the same structural scheme, the larger the skew angle, the greater the hydro-elastic structural responses of the composite propeller. The change of the structural responses is not significant for the non-skewed and low-skewed composite propellers in the range of full advance coefficient, however, the change is great for the high-skewed composite propellers.

(4) We can adjust the structural scheme according to the skew angle, so that the series of composite propeller obtain the desired efficiency, cavitation and structural performance.

(5) The research of cavitation performances of the same series of composite propellers is a very important part for understanding the composite propeller, and it is 
a very complex problem. We will discuss further in future work.

\section{Acknowledgement}

This work is supported by Key Laboratory Open Fund and Programme for Changjiang Scholars and Innovative Research Team in University.

\section{Reference}

1) Mouritz, A., Gellert, E., Burchill, P., Challis, K., 2001. Review of advanced composite structures for naval ships and submarines. Composite Structures. $53,21-41$.

2) George, M., 2004. A new start for marine propellers. Reinforced plastics. 12, $34-38$

3) Lin, G., 1991. Comparative stress deflection analyses of a thick shell composite propeller blade. Technical Report: DTRC/SHD-1373-01, David Taylor Research Center.

4) Lin, G., 1991. Three-dimensional stress analyses of a fiber reinforced composite thruster blade. Symposium on Propellers/Shafting, Society of Naval Architects and Marine Engineers, Virginia Beach, VA, USA.

5) Lee, Y.J., Lin, C.C., 2004. Optimized design of composite propeller. Mechanics of Advanced Materials and Structures. 11, 17-30.

6) Lin, C.C., Lee, Y.J., Hung, C.S., 2009. Optimization and experiment of composite marine propellers. Composite Structures. 89, 206-215.

7) Lin, H.J., Lin, J.J., 2005. Strength evaluation of a composite marine propeller 
blade. Journal of reinforced plastics and composites. 24, 1791-1807.

8) Lin, H.J., Tsai, J.F., 2008. Analysis of underwater free vibrations of a composite propeller blade. Journal of Reinforced Plastics and composites. 27( 5), 447-458.

9) Motley, M.R., Liu, Z, Young, Y.L, 2009. Utilizing fluid-structure interactions to improve energy efficiency of composite marine propellers in spatially varying wake. Composite Structures. 90, 304-313.

10) Young, Y.L., 2008. Fluid-structure interaction analysis of flexible composite marine propellers. Journal of Fluids and Structures. 24, 799-818.

11) Liu, Z., Young, Y.L., 2009. Utilization of bend-twist coupling for performance enhancement of composite marine propellers. Journal of Fluids and Structures. 25, 1102-1116.

12) Young, Y.L. 2010. Dynamic hydroelastic scaling of self-adaptive composite marine rotors. Composite Structures. 92, 97-106.

13) Motley, M.R., Young, Y.L, 2011. Performance-based design and analysis of flexible composite propulsors. Journal of Fluids and Structures. 27, $1310-1325$.

14) Paik, B.G., Kim, G.D., Kim, K.Y., Seol, H.S., Hyun. B.S., Lee. S.G., Jung. Y.R., 2013. Investigation on the performance characteristics of the flexible propellers. Ocean Engineering. 73, 139-148.

15) Mulcahy, N.L., Prusty, B.G., Gardiner, C.P., 2010. Hydroelastic tailoring of flexible composite propellers. Ships and Offshore Structures. 5(4), 359-370. 
16) Herath, M.T., Natarajan, S., Prusty, B.G., John, N.S., 2013. Smoothed finite element and genetic algorithm based optimization for shape adaptive composite marine propellers. Composite Structures. 109(6), 189-197.

17) Herath, M.T., Natarajan, S., Prusty, B.G., John, N.S., 2015. Iso-geometric analysis and Genetic Algorithm for shape-adaptive composite marine propellers. Computer Methods in Applied Mechanics and Engineering. 284, 835-860.

18) Weitzenböck, J.R., Shenoi, R.A., Wilson, P.A., 1999. Radial flow permeability measurement. Part A: Theory. Composites Part A: Applied Science and Manufacturing. 30 (6), 781-79.

19) Weitzenböck, J.R., Shenoi, R.A., Wilson, P.A., 1999. Radial flow permeability measurement. Part B: Application. Composites Part A: Applied Science and Manufacturing. 30 (6), 797-813.

20) Xing, J., Shenoi, R.A., Wilson, P.A., Xing, J.T., 2004. Fluid flow through porous media subjected to a boundary condition of variable pressure. Proceedings of the Royal Society A Mathematical Physical \& Engineering Sciences. 460, 1905-1920.

21) Lee, H., Song, M.C., Suh, J.C., Cha, M.C., Chang, B.Jun., 2015. A Numerical Study on the Hydro-elastic Behavior of Composite Marine Propeller. Fourth International Symposium on Marine Propulsors.

22) Carlton, J., 2010. Marine propellers and propulsion, Elsevier, Third edition. 108-109. 
23) Taylor, R.L., Beresford, P.J., 1976. A non-conforming element for stress analysis. Int. J. Numer. Methods Eng. 10, 1211-1219.

24) Menter, F.R., 1994. Two-equation eddy-viscosity turbulence models for engineering applications. AIAA-J. 32, 1598 - 1605.

25) He, X.D., Hong, Y., Wang, R.G., 2012. Hydroelastic optimisation of a composite marine propeller in a non-uniform wake. Ocean Engineering. 39:14-23.

26) Boswell R.J., 1971. Design, cavitation performance and open water performance of a series of research skewed propellers. NSRDC Report No. 3339. 


\section{Figures}

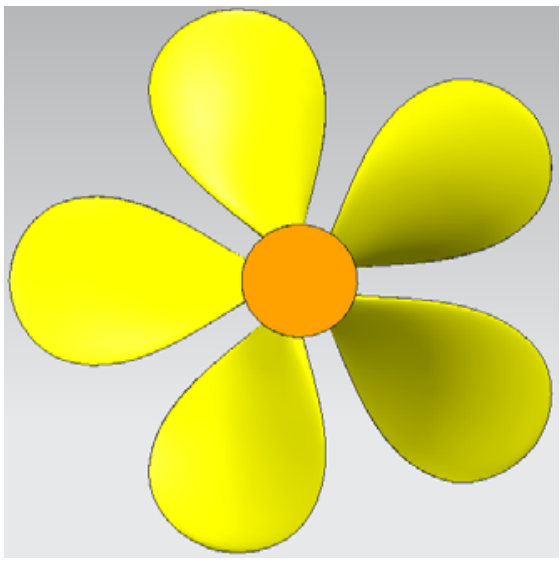

a) 4381

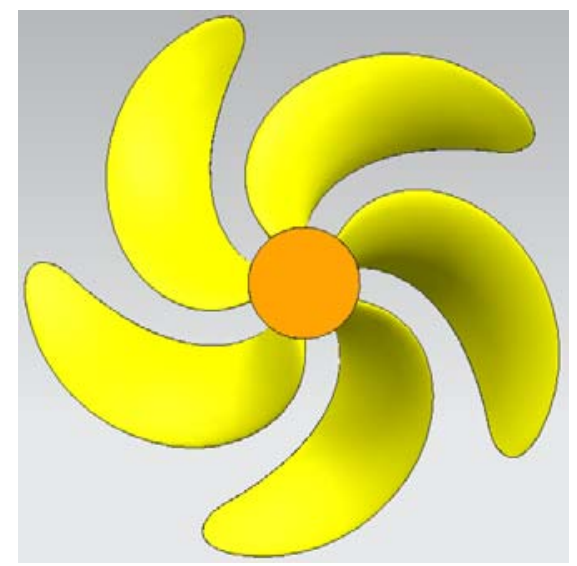

c) 4383

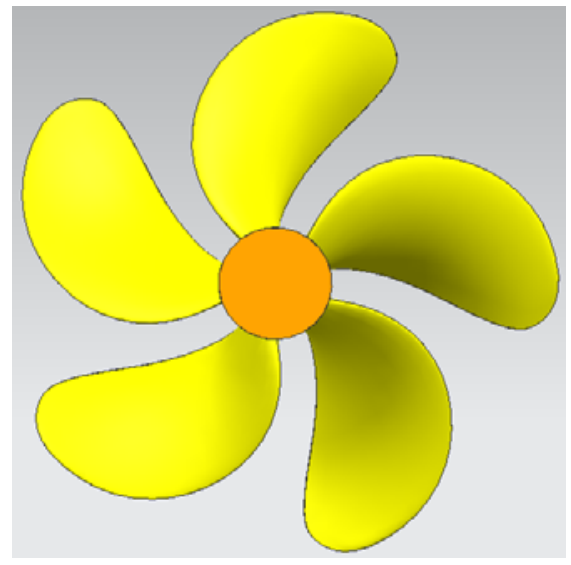

b) 4382

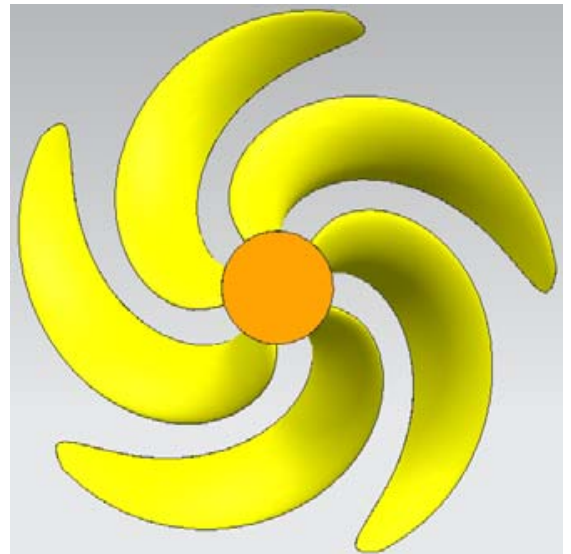

d) 4384

Fig 1 The geometries of the $438 x$ series propeller

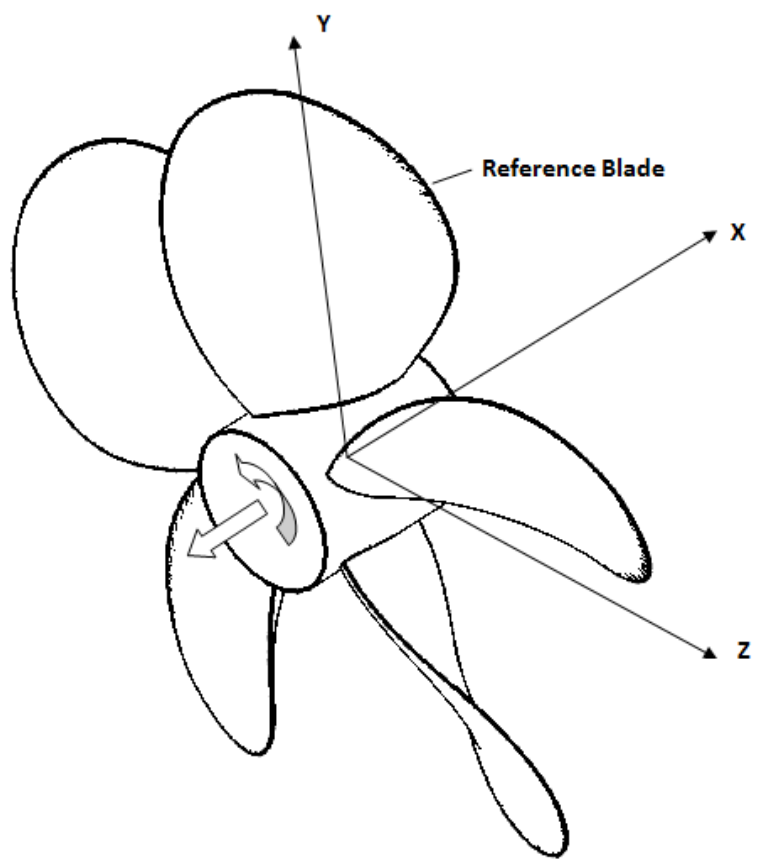

Fig 2 Coordinate system of composite propeller 


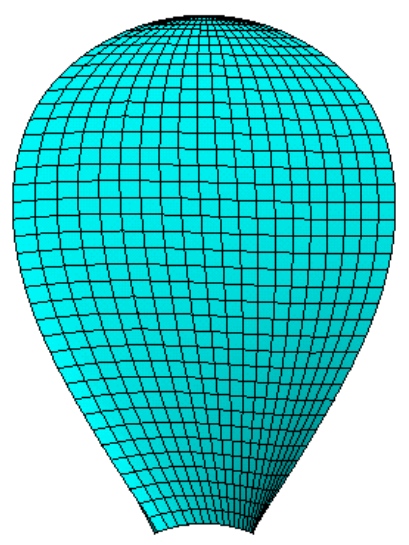

a) 4381

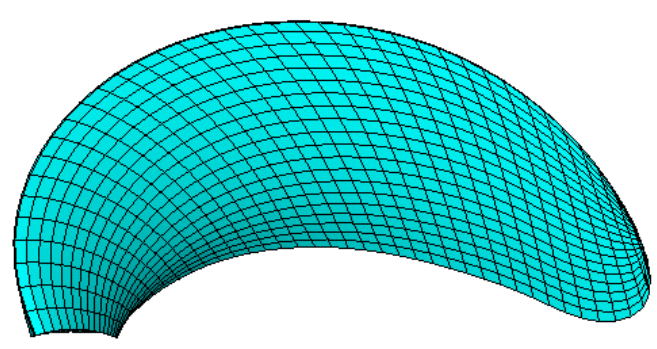

c) 4383

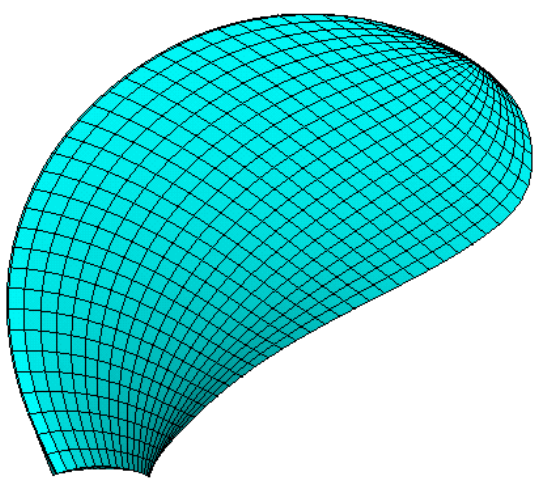

b) 4382
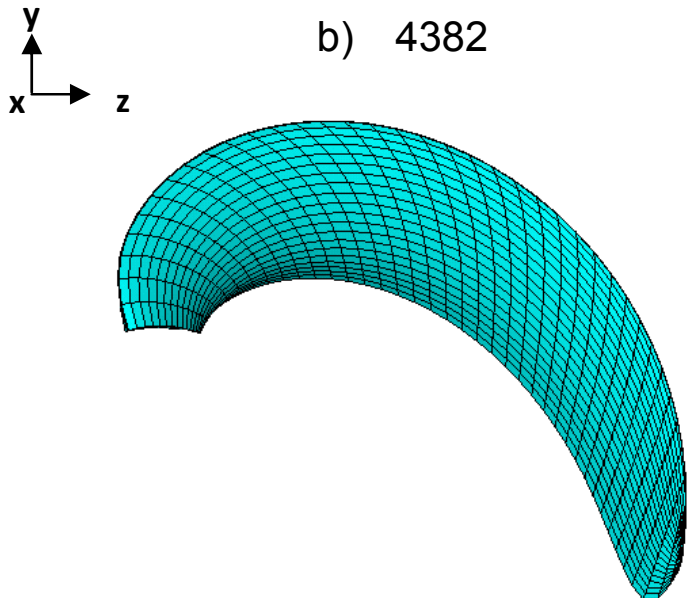

d) 4384

Fig 3 Finite element models of the $438 x$ series of composite propeller

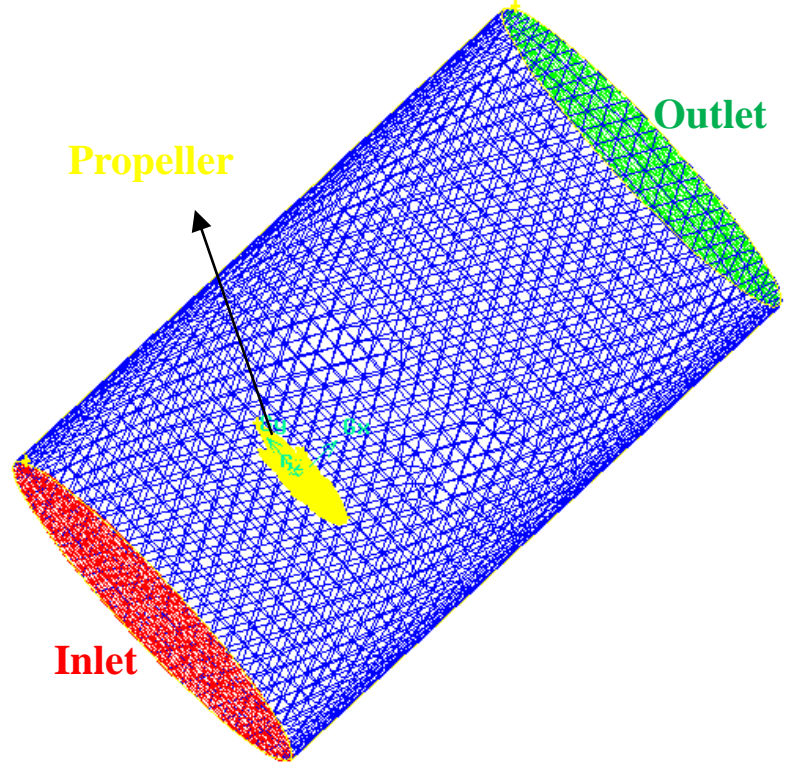

Fig 4 The fluid meshes of the computation region 
(a) 4381

(c) 4383

(b) 4382

(d) 4384

Fig 5 The detailed mesh of the $438 x$ series propeller blade 


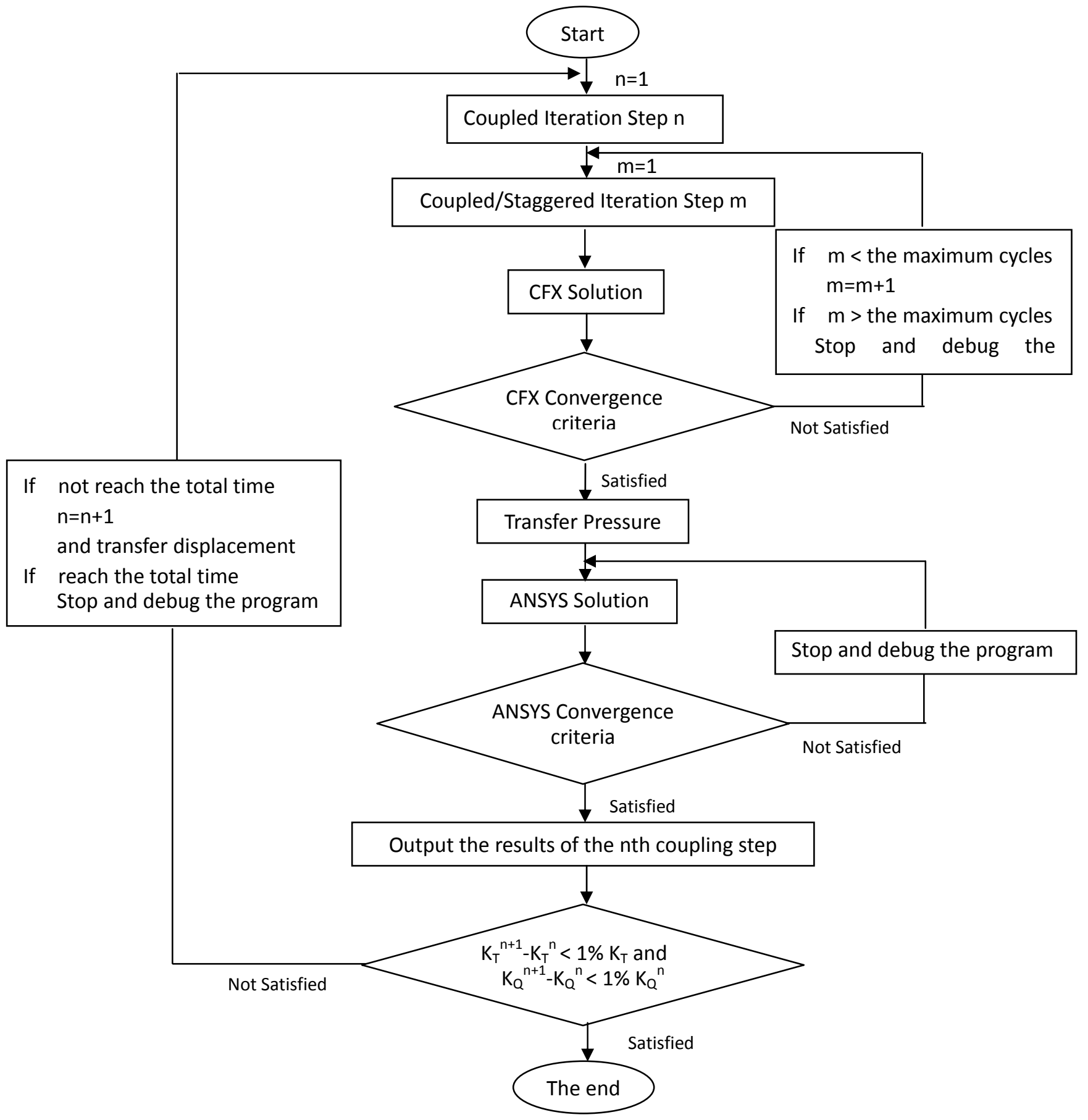

Fig 6 The coupling iteration process 


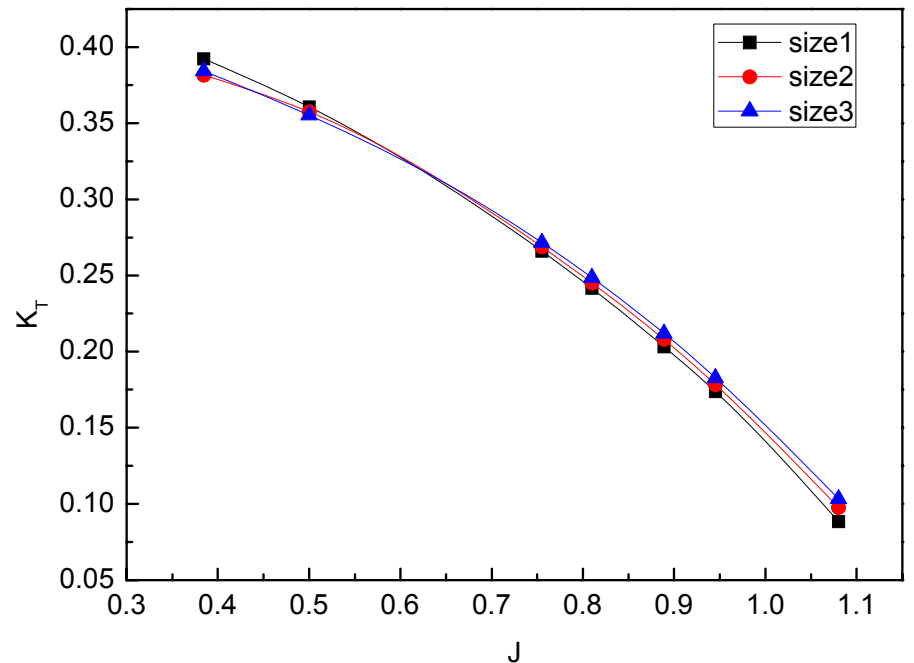

Fig 7 Convergence of the thrust coefficient with different grid sizes for 4381 propeller

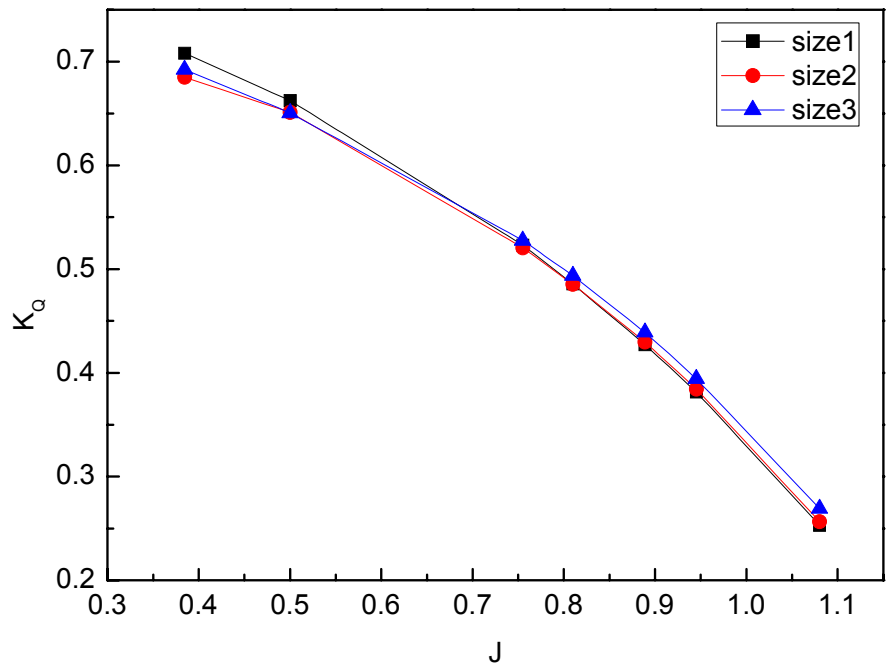

Fig 8 Convergence of the torque coefficient with different grid sizes for 4381 propeller 


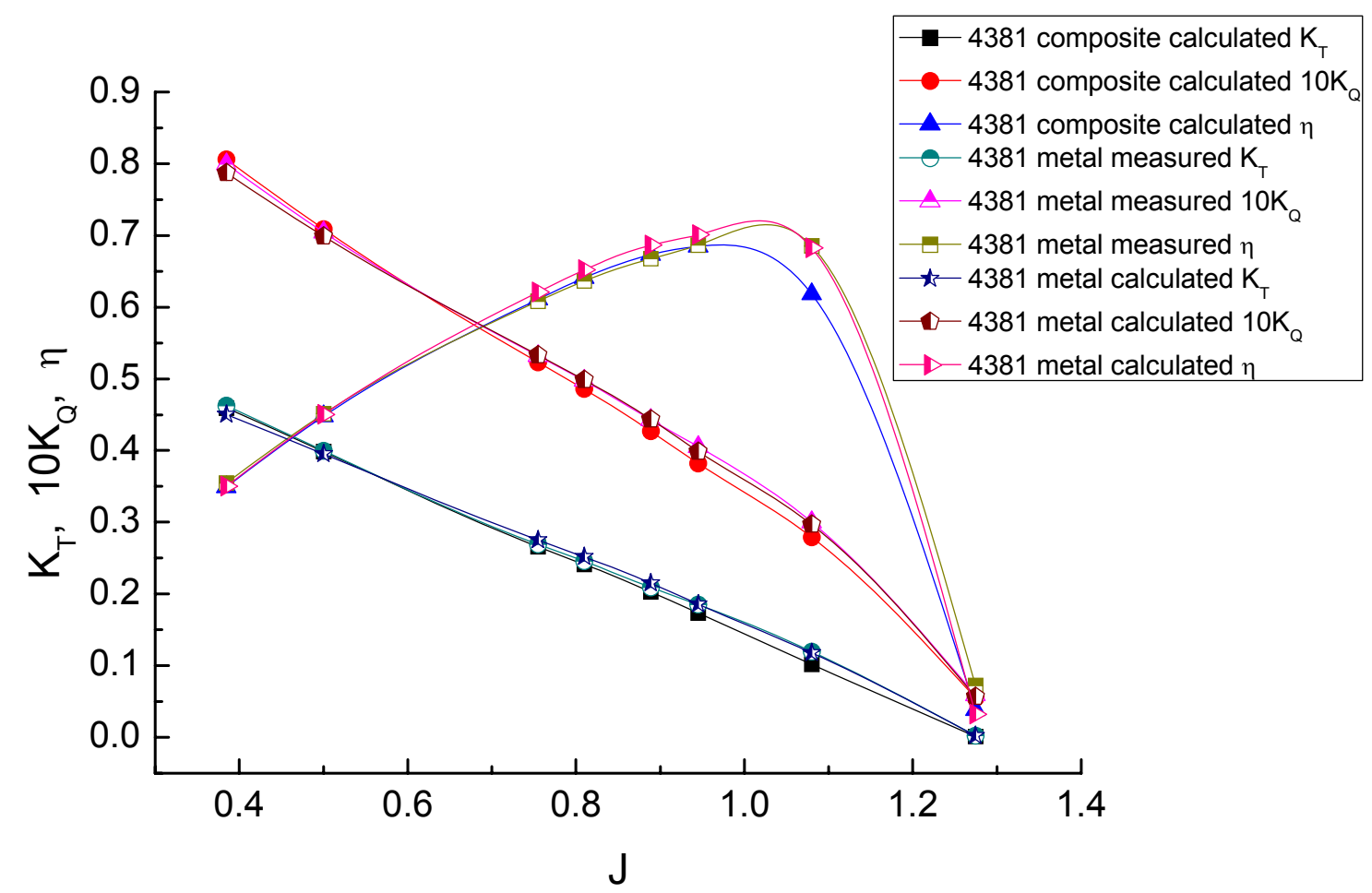

Fig 9 Comparison of the hydrodynamic performances of 4381 composite propeller and 4381 metal propeller

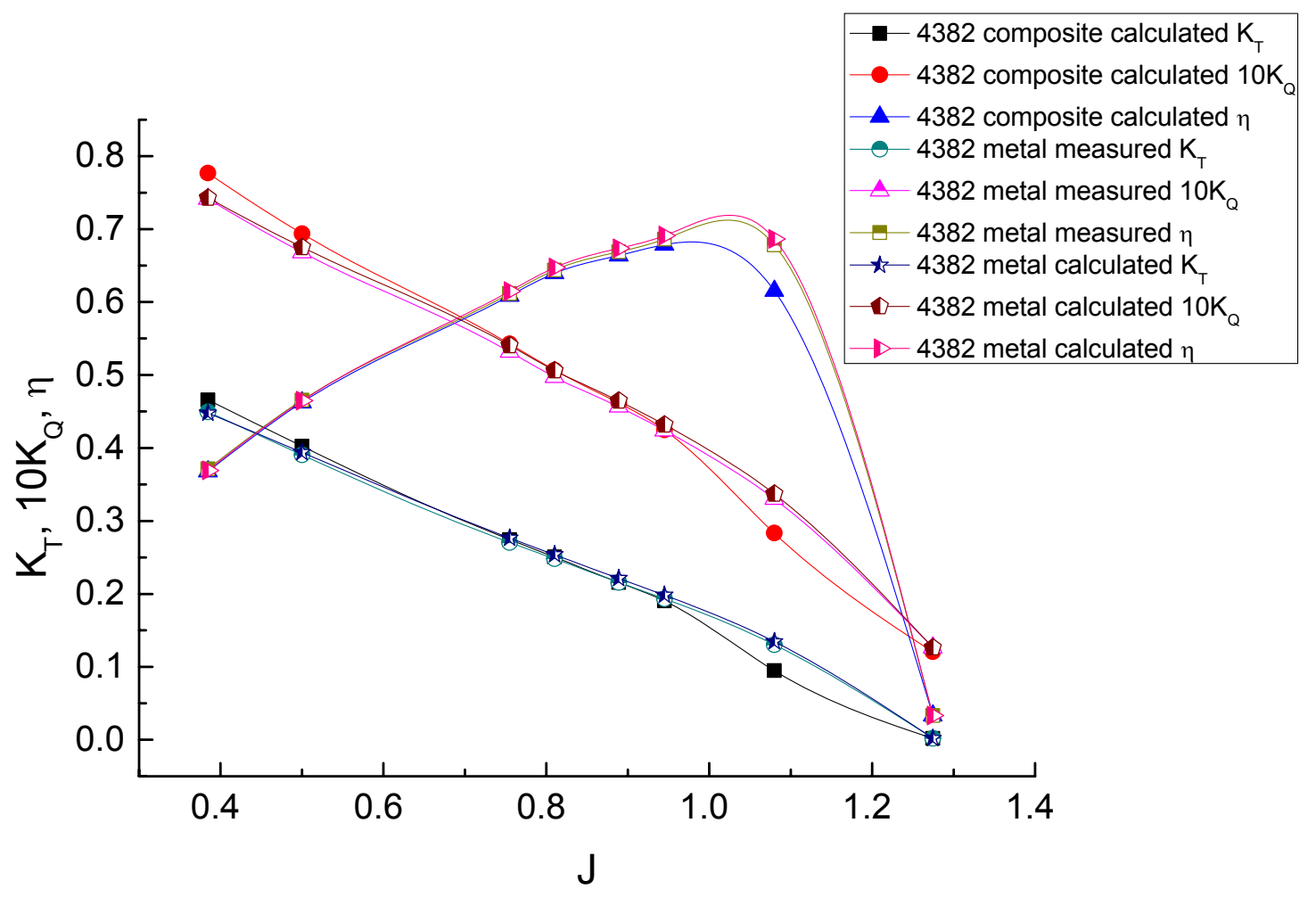

Fig 10 Comparison of the hydrodynamic performances of 4382 composite propeller and 4382 metal propeller 


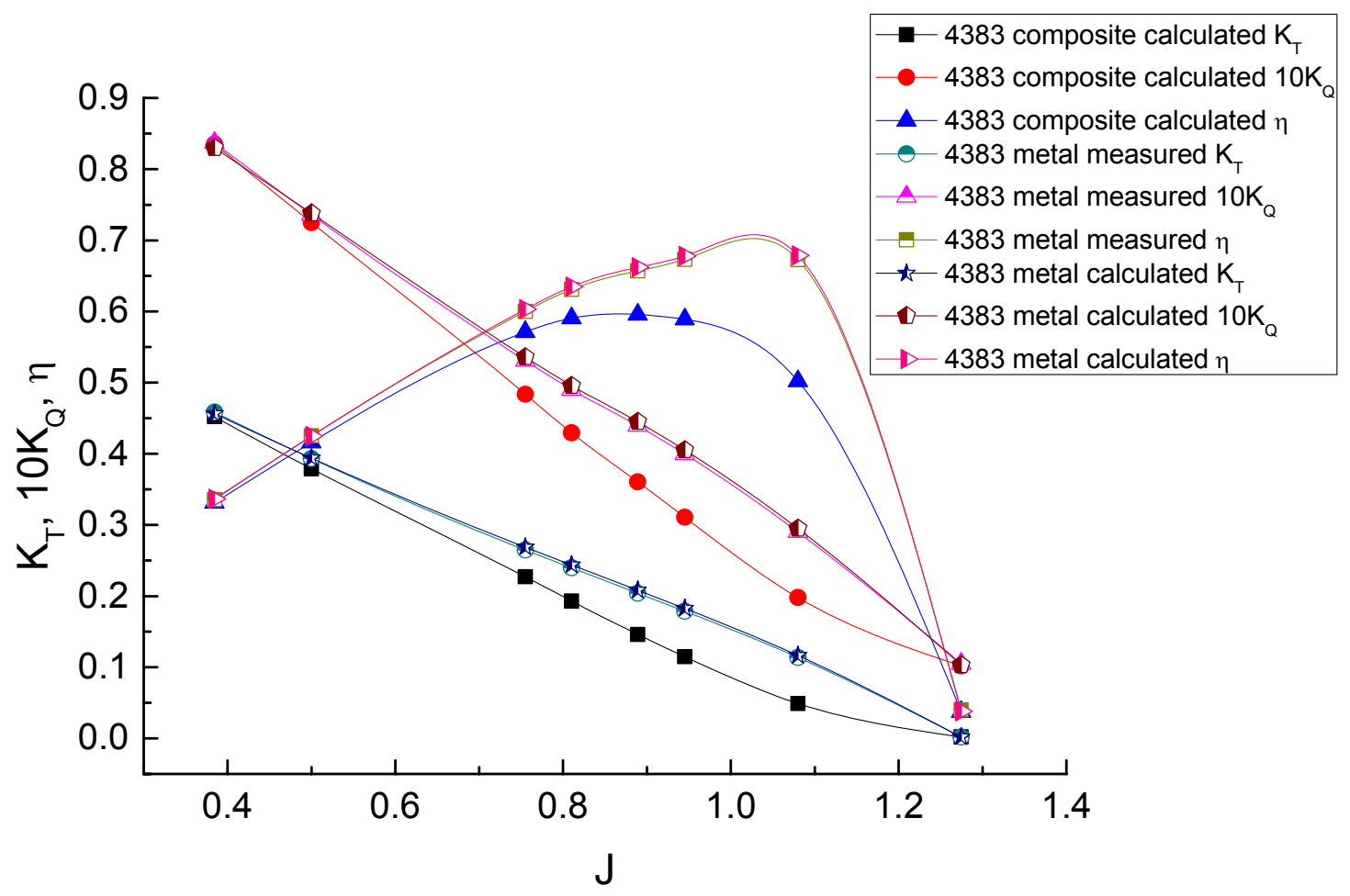

Fig 11 Comparison of the hydrodynamic performances of 4383 composite propeller and 4383 metal propeller

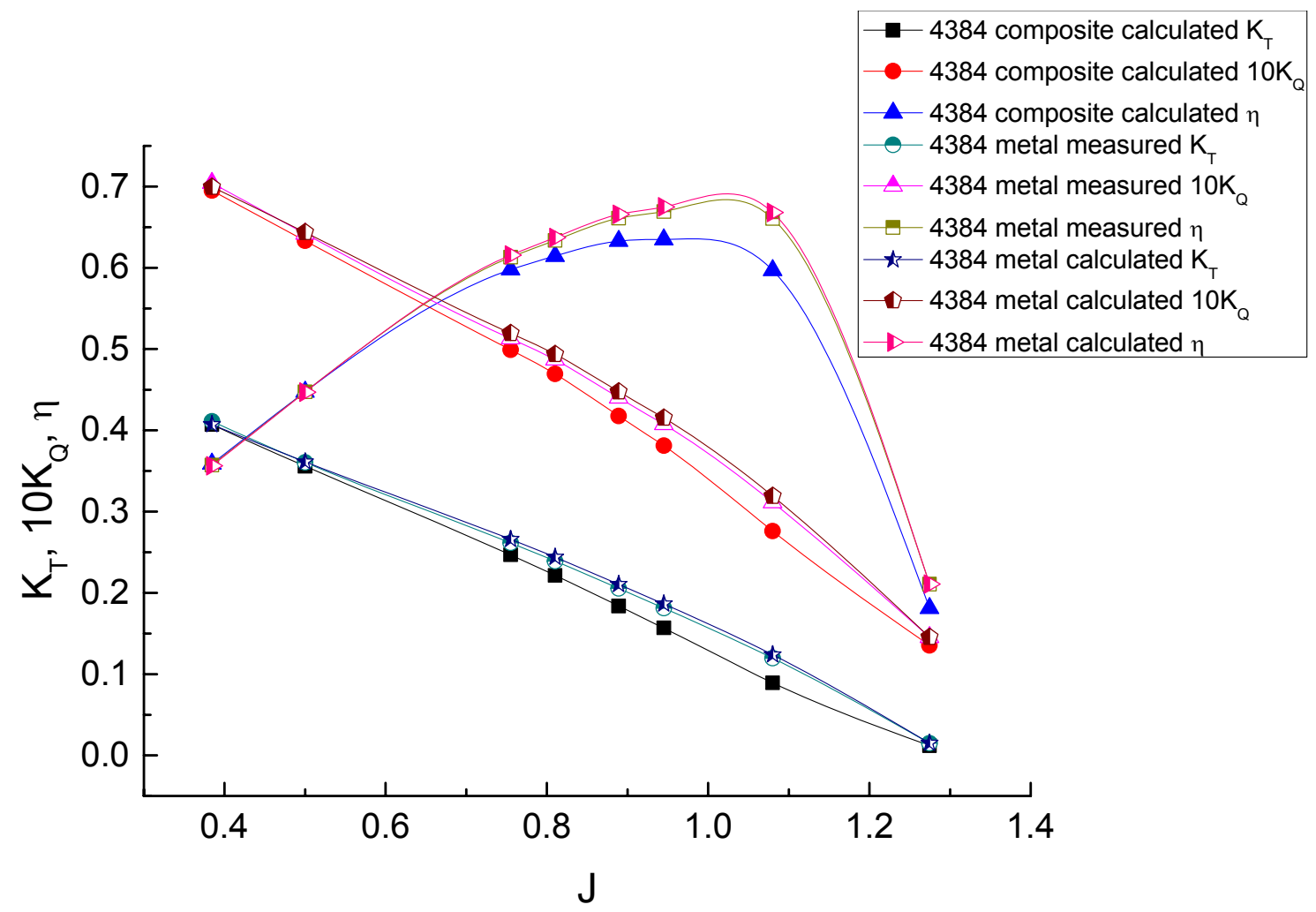

Fig 12 Comparison of the hydrodynamic performances of 4384 composite propeller and 4384 metal propeller 

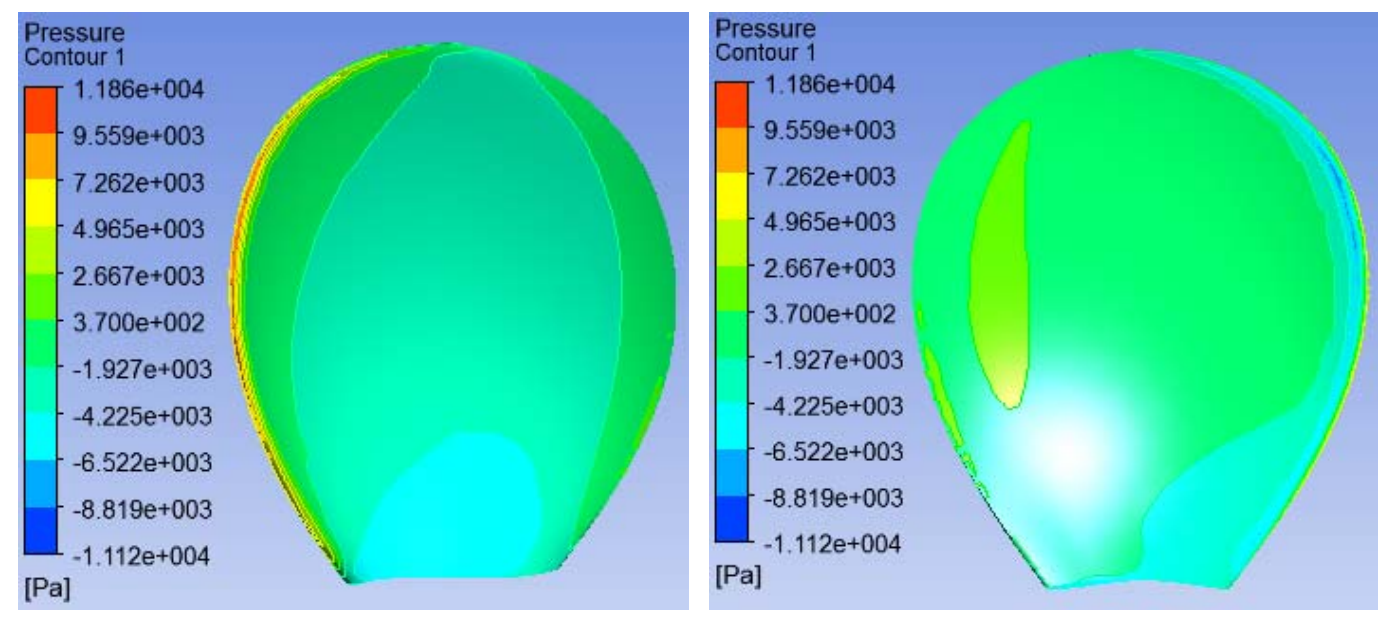

(a) 4381

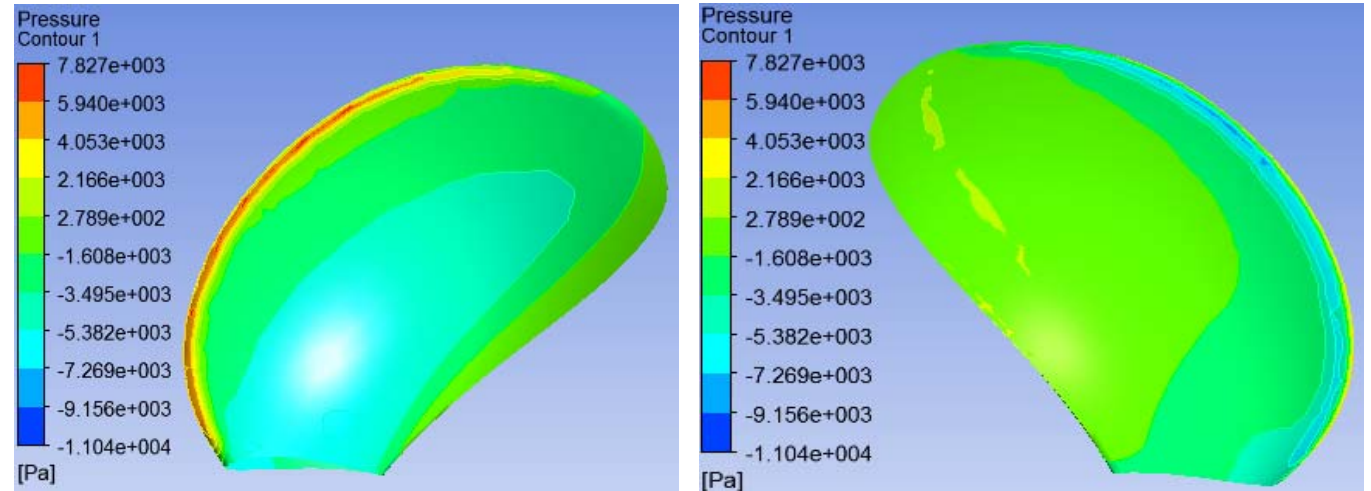

(b) 4382
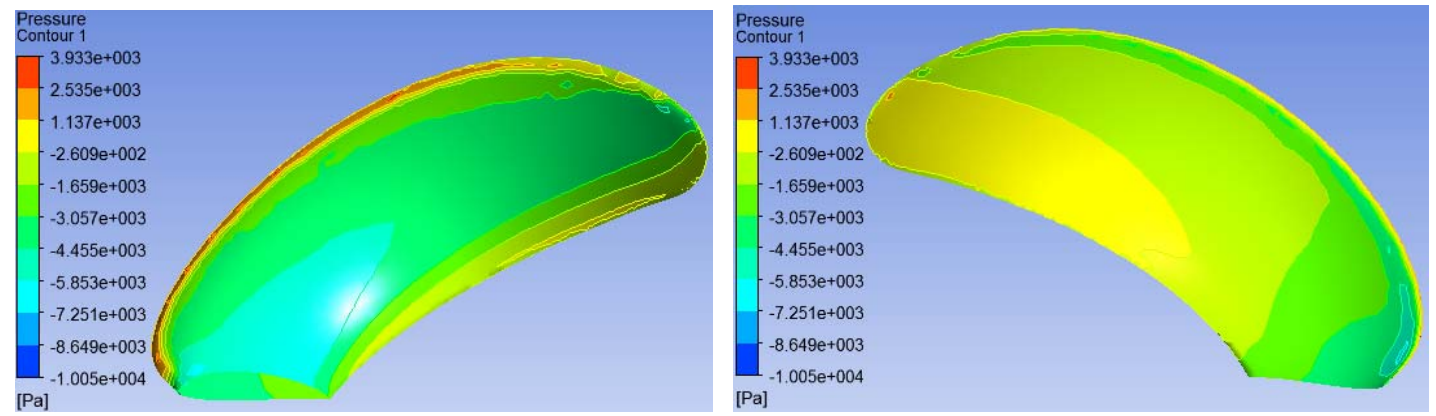

(c) 4383

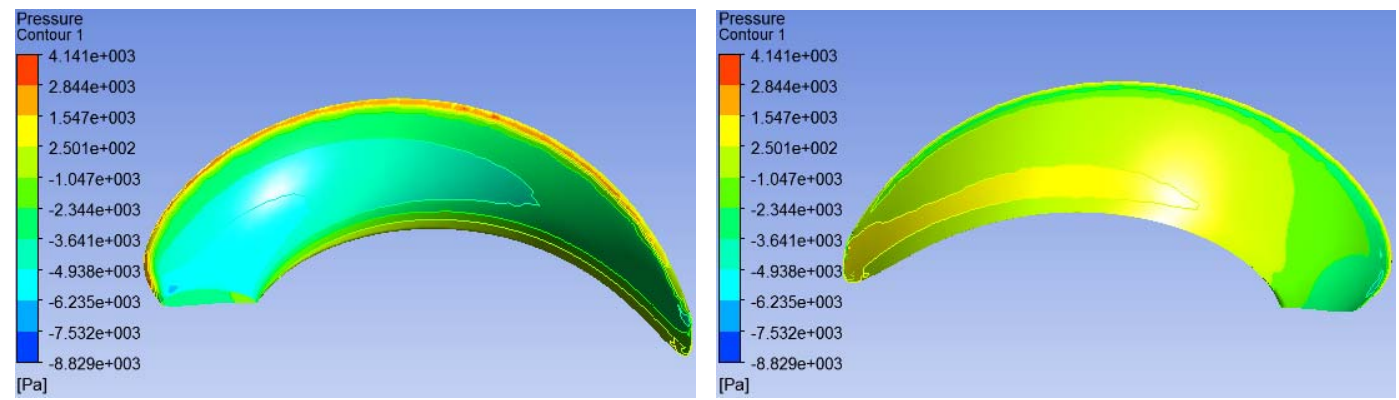

(d) 4384

Fig 13 Compare the pressure distributions of the $438 x$ series of composite propellers $(\mathrm{J}=1.08)$ 

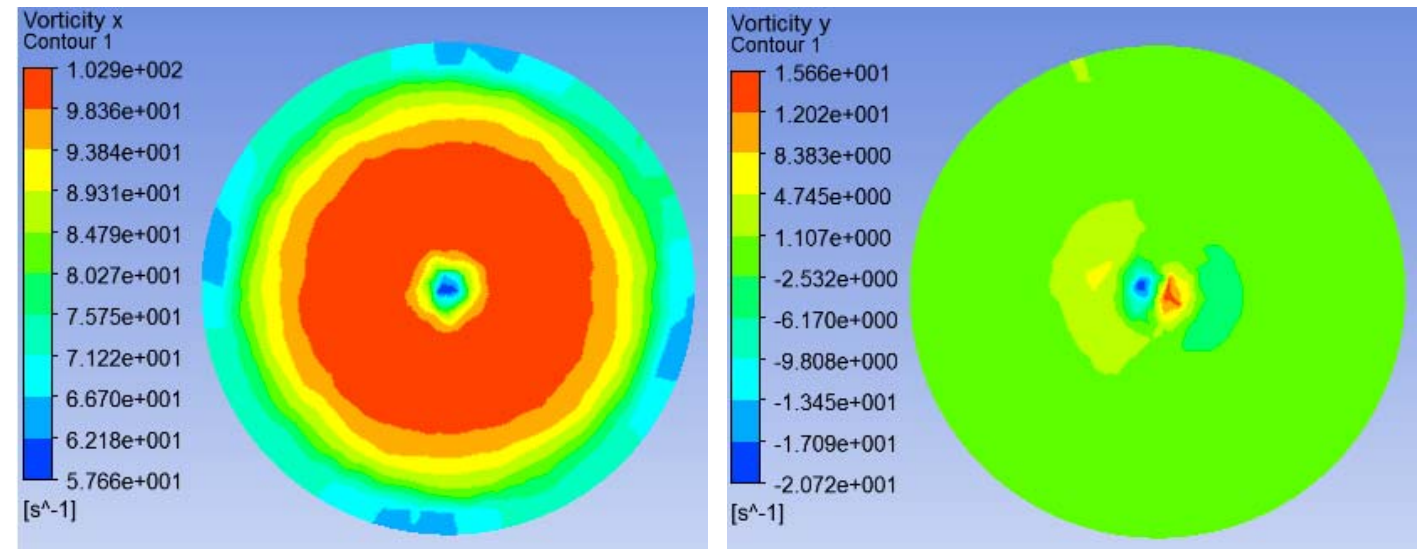

(a) 4381 (Left: flow direction; Right: rotating direction)
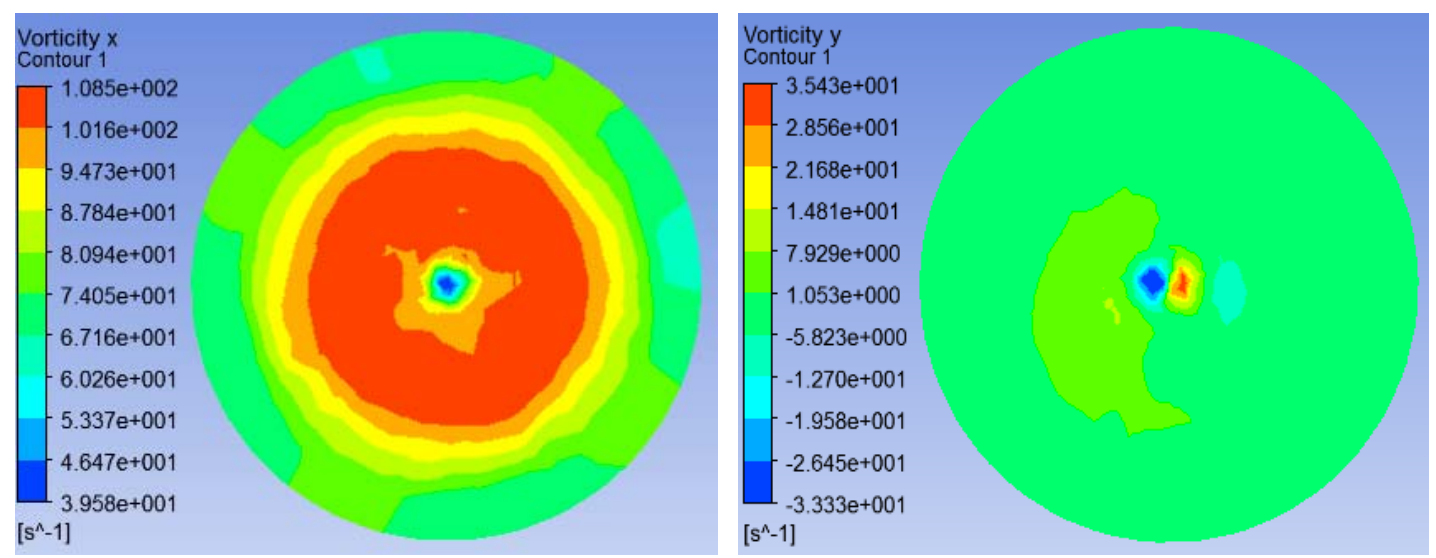

(b) 4382 (Left: flow direction; Right: rotating direction)
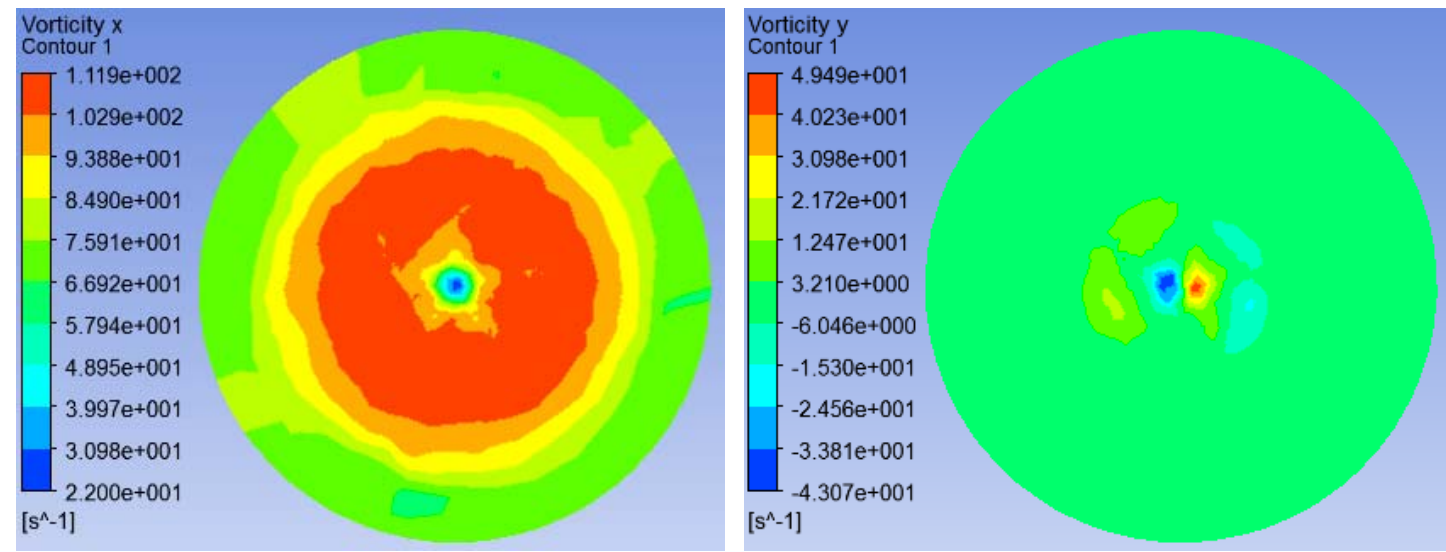

(c) 4383 (Left: flow direction; Right: rotating direction) 

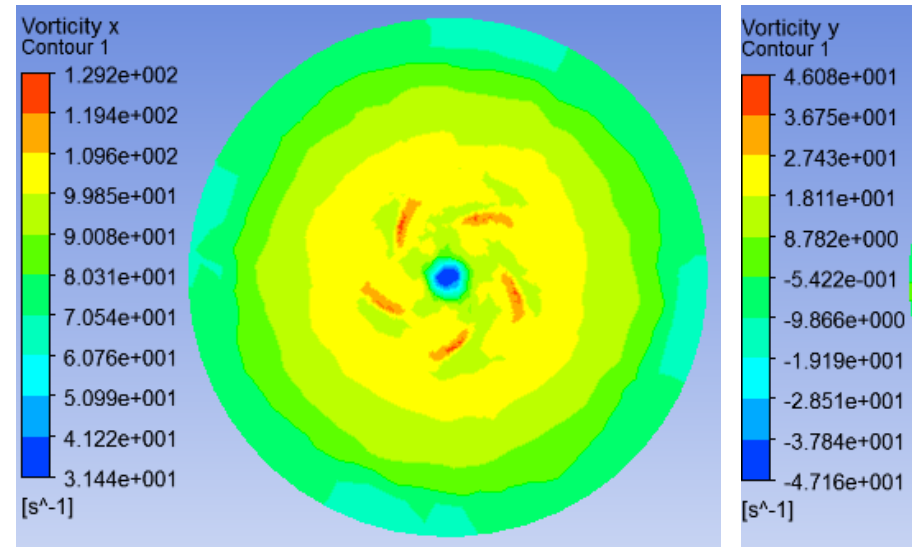

(d) 4384(Left: flow direction; Right: rotating direction)

Fig 14 The vorticity contours of the $438 x$ series of composite propellers $(\mathrm{J}=1.08)$

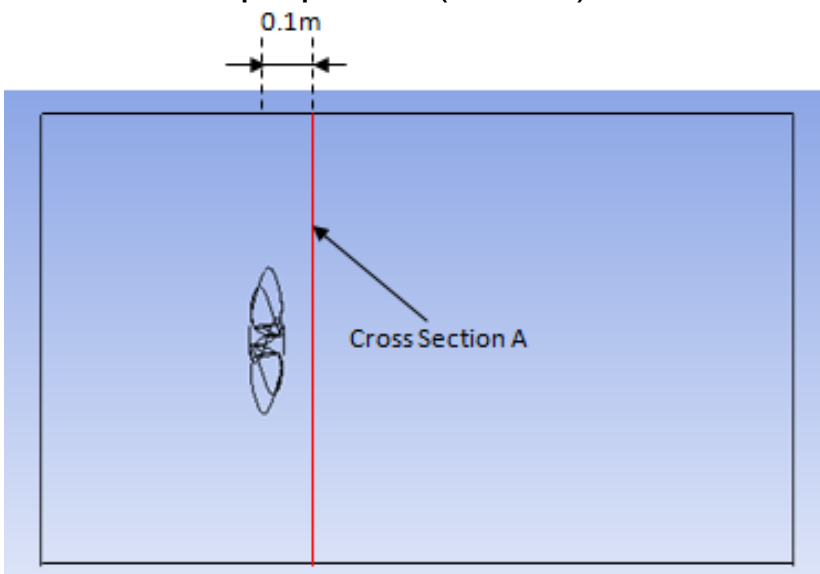

Fig 15 The schematic view of the cross-section A

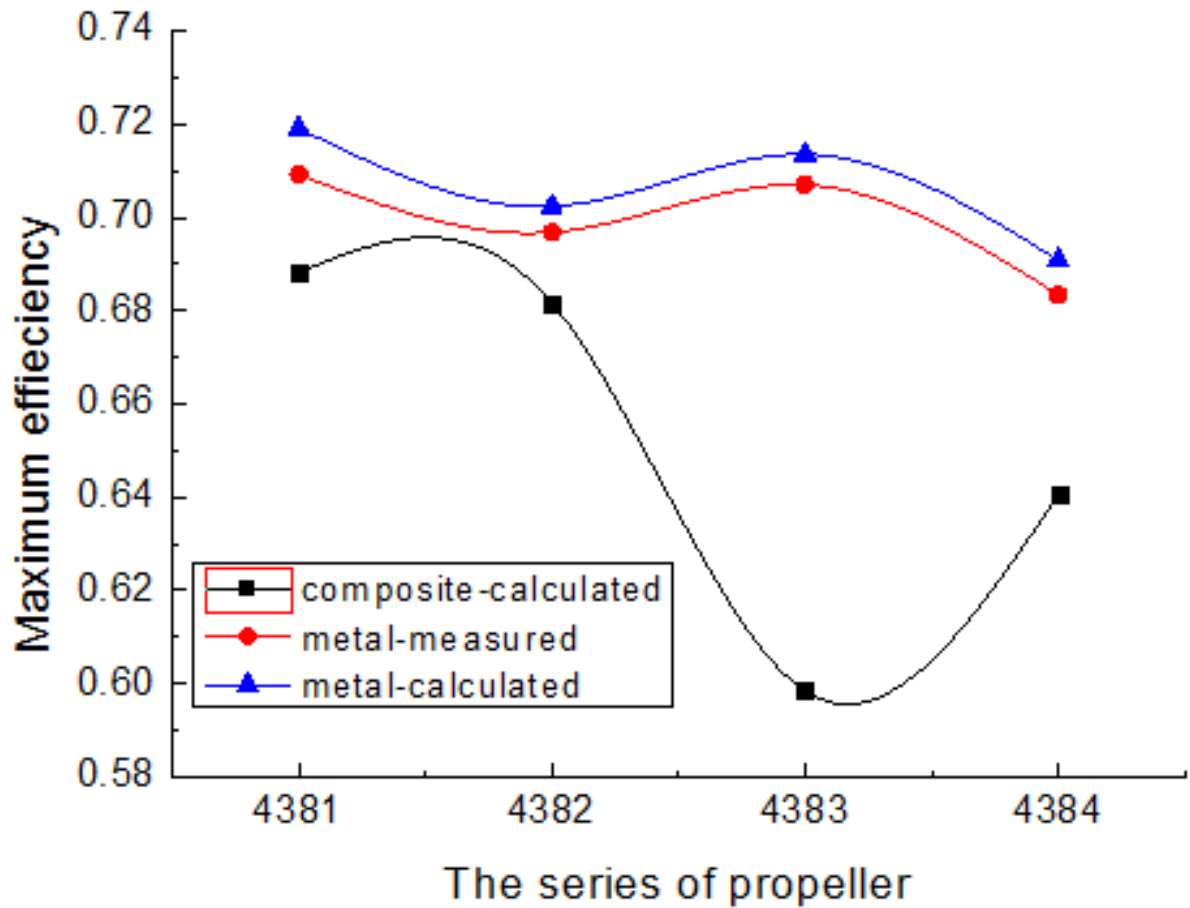

Fig 16 Comparison of the maximum efficiency of $438 x$ series of composite propellers and $438 x$ series of metal propellers 


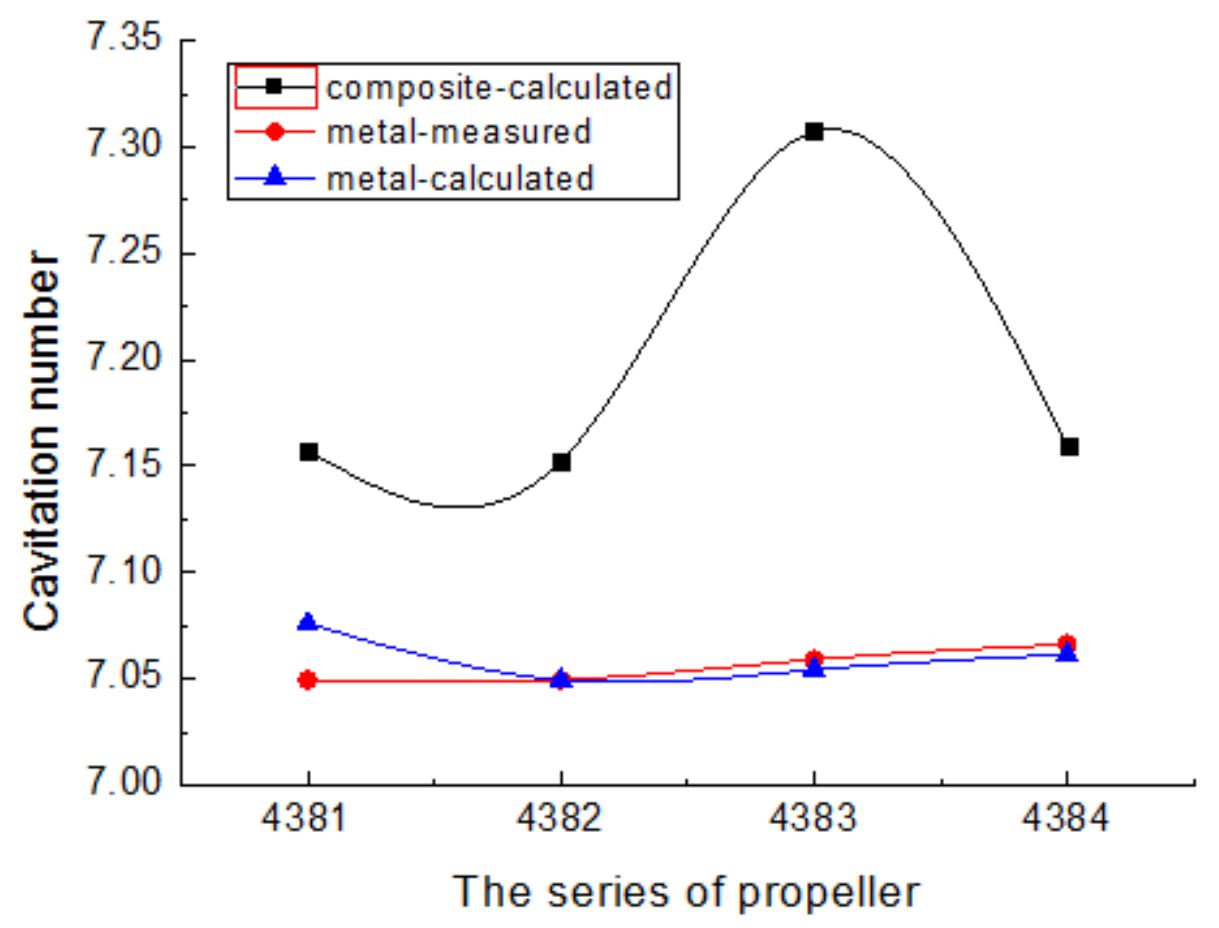

Fig 17 Compare the cavitation number corresponding to the maximum efficiency of the $438 x$ series of propellers

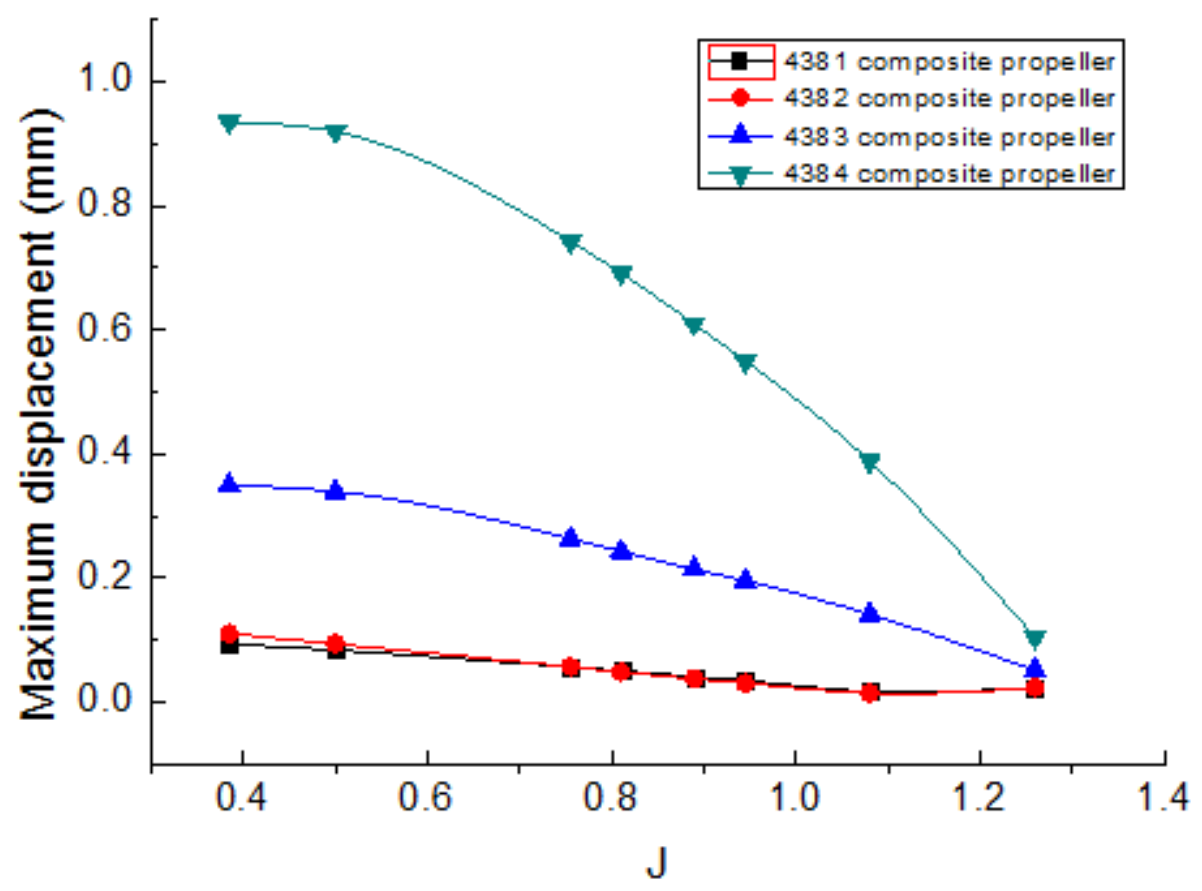

Fig 18 Compare the maximum displacements of the $438 x$ series of composite propellers 


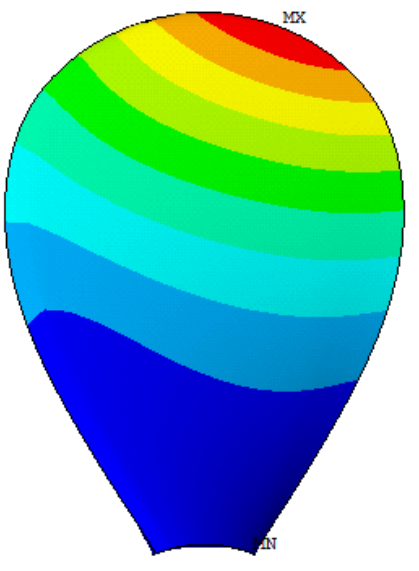

(a) 4381

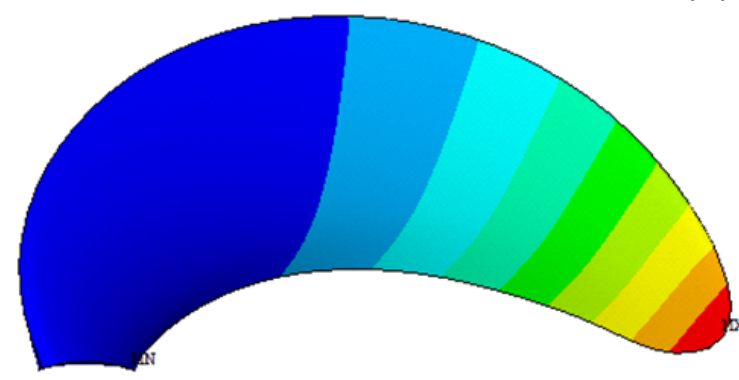

(c) 4383

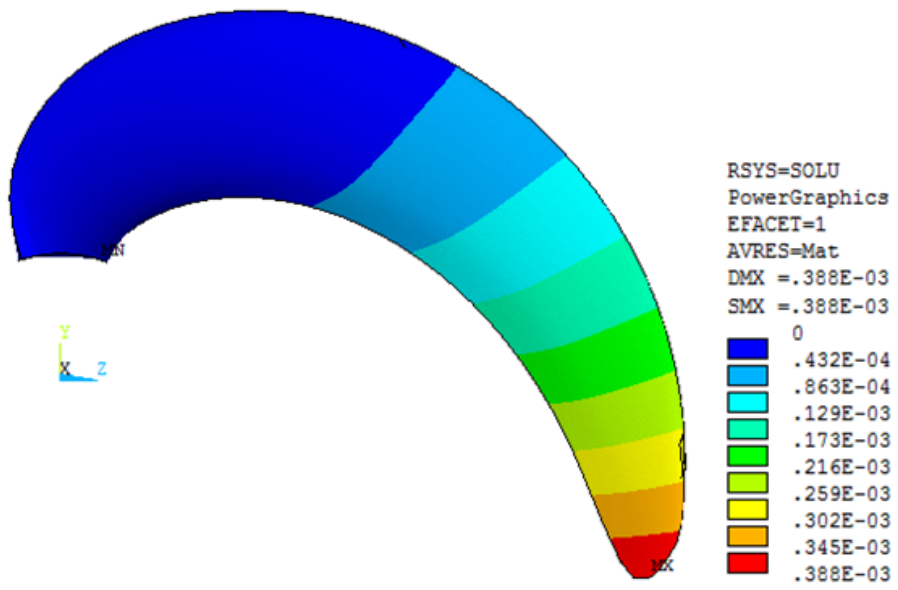

(d) 4384

Fig 19 The deformation contours of the $438 x$ series of composite propellers $(\mathrm{J}=1.08)$

RSYS $=$ SOLU

EFACET $=1$

AVRES $=$ Mat

$\mathrm{DMX}=.148 \mathrm{E}-04$ $\mathrm{SMX}=.148 \mathrm{E}-04$ 0
$165 \mathrm{E}-0$

$.329 \mathrm{E}-05$
$.494 \mathrm{E}-05$

$\square \quad .659 \mathrm{E}-05$

$\square .988 \mathrm{E}-05$

$.132 \mathrm{E}-04$
$\square .148 \mathrm{E}-04$

(b) 4382

PowerGraphics

EFACET $=1$

$\mathrm{DMX}=.142 \mathrm{E}-03$

$\operatorname{SMX}=.142 \mathrm{E}-03$

. $.157 \mathrm{E}-04$

$.472 \mathrm{E}-0$

$.629 \mathrm{E}-04$
$.786 \mathrm{E}-0$

$944 \mathrm{E}-0$

$110 \mathrm{E}-03$

$.142 \mathrm{E}-03$

$148 \mathrm{E}-04$

PowerGraphic

$\mathrm{X}=388 \mathrm{E}-03$

$\mathrm{MX}=.388 \mathrm{E}-03$ 


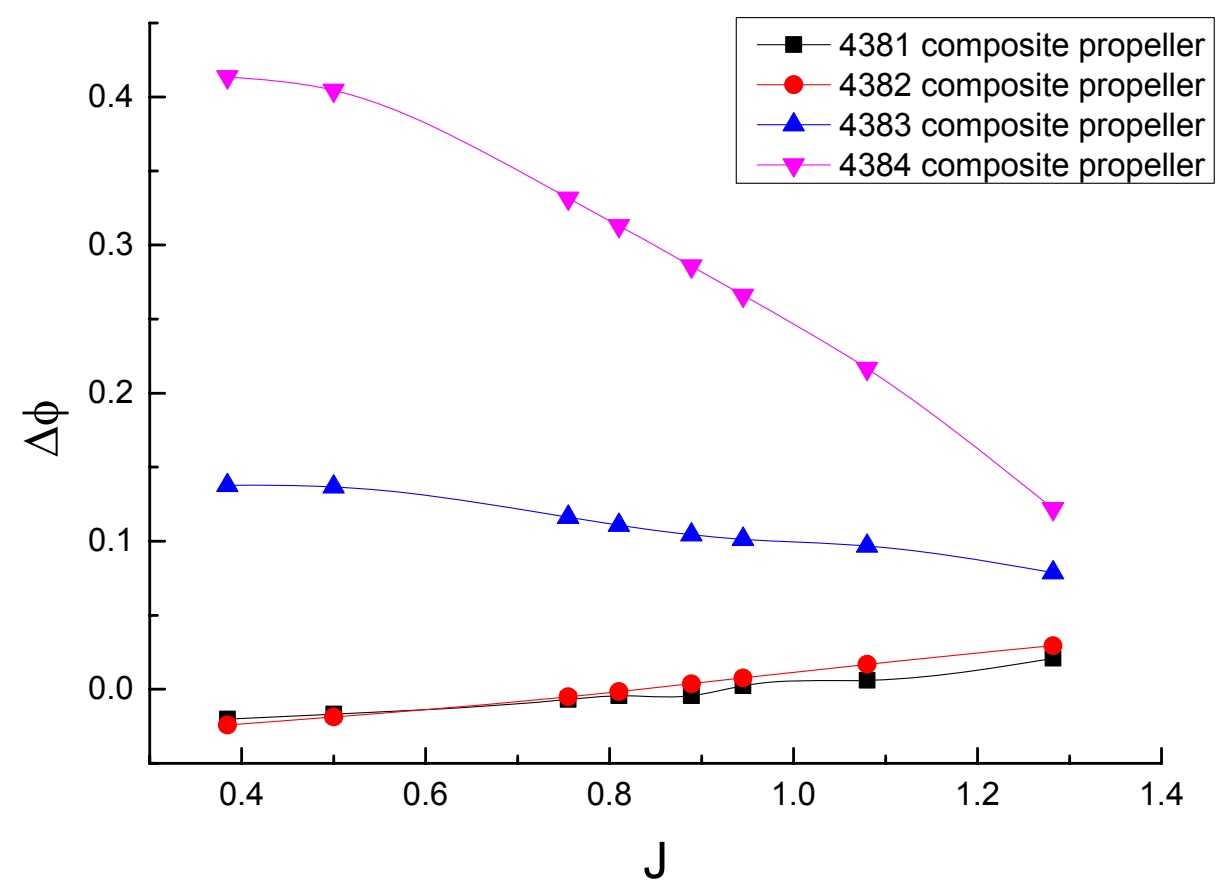

Fig 20 Compare the pitch angle changes at the blade tip of the $438 x$ series of composite propellers

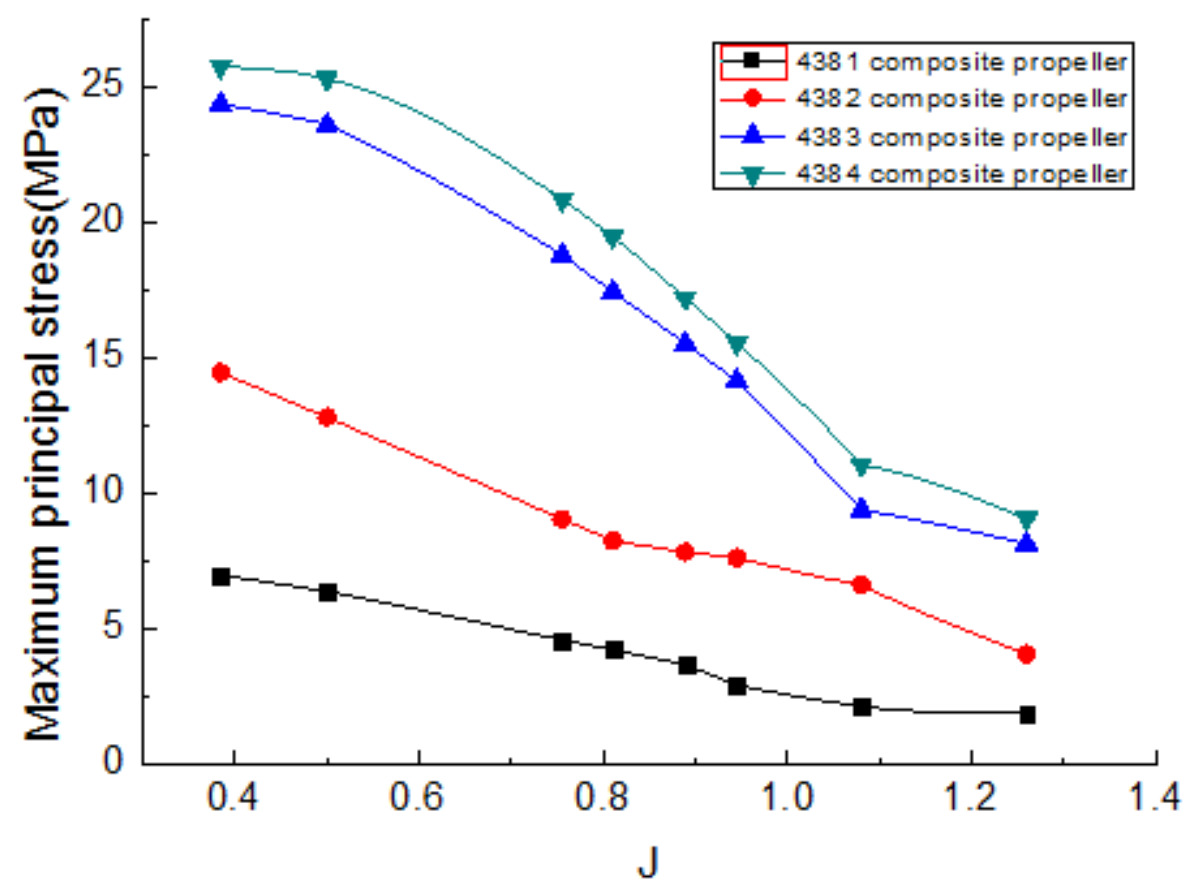

Fig 21 Compare the maximum principal stresses of the $438 x$ series of composite propellers 


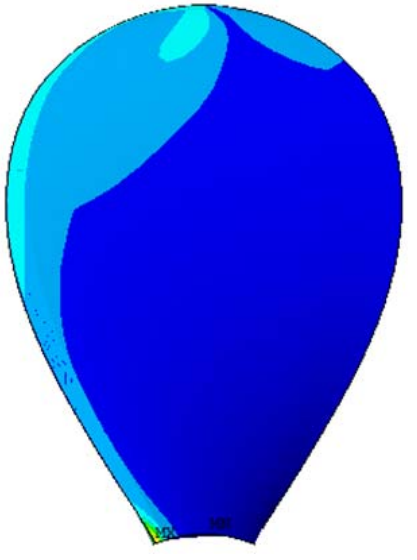

(a) 4381

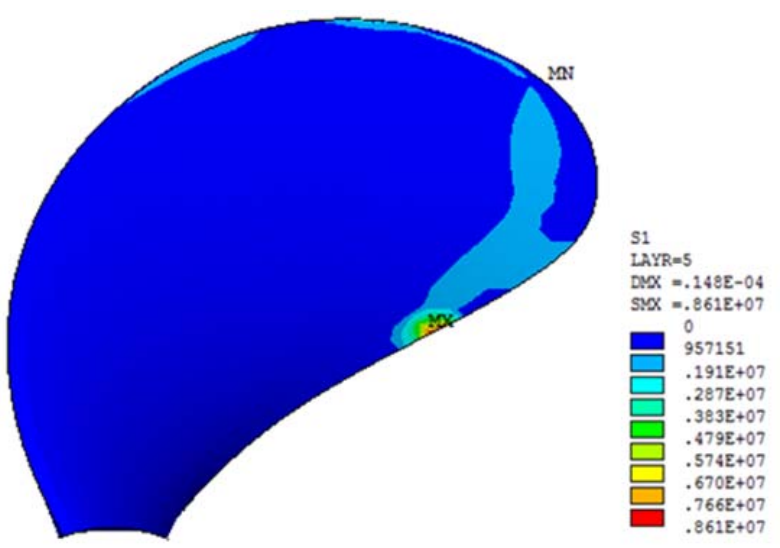

(b) 4382

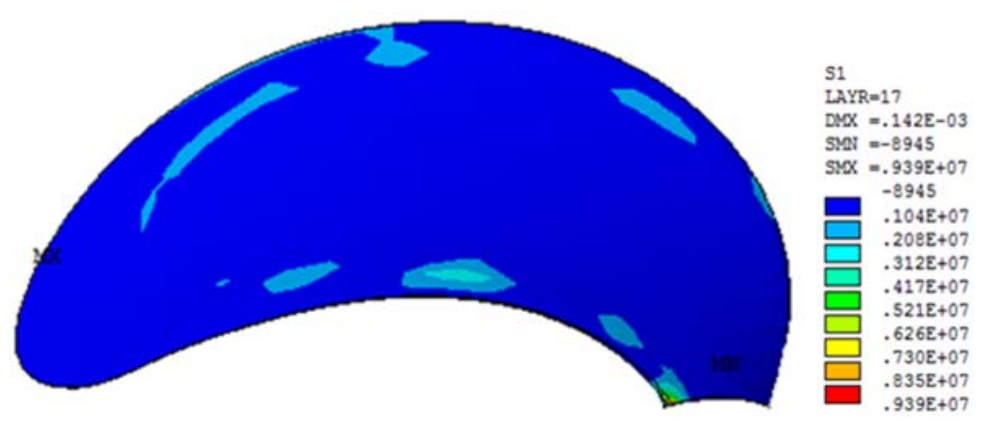

(c) 4383

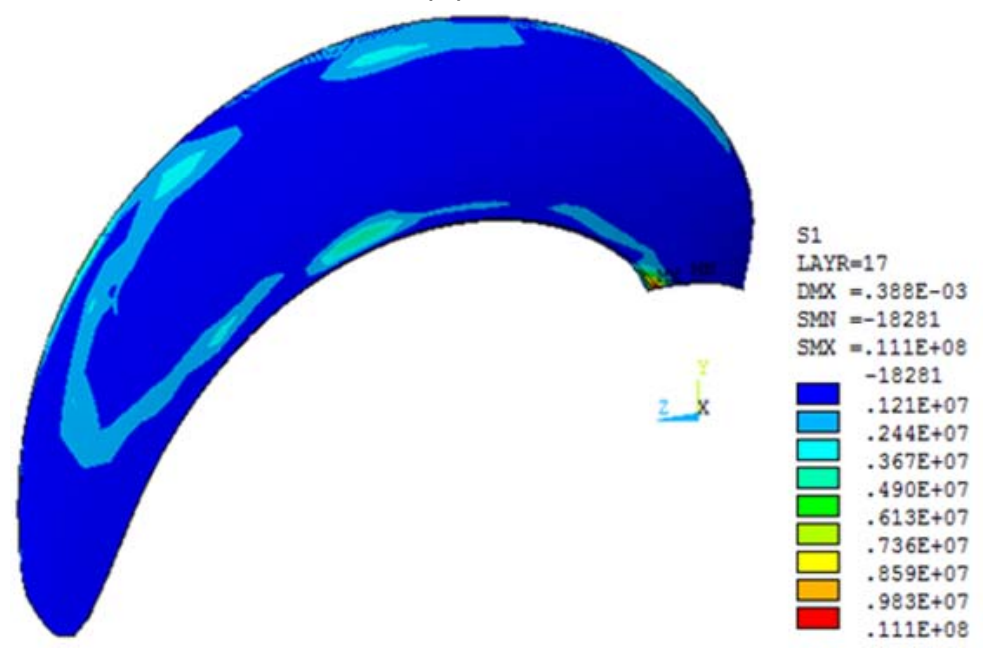

(d) 4384

Fig 22 The principal stress contours of the 438x series of composite propellers at the layer corresponding the maximum principal stress $(\mathrm{J}=1.08)$ 
Tables

Table 1 Material properties

\begin{tabular}{cccc}
\hline Properties & UC & SC & Metal \\
\hline $\begin{array}{c}\text { Longitudinal modulus } \\
\mathrm{E}_{1}(\mathrm{~Pa})\end{array}$ & $1.35 \mathrm{e} 11$ & $7.626 \mathrm{e} 10$ & $1.27 \mathrm{e} 11$ \\
Transverse modulus & $9.4 \mathrm{e} 9$ & $7.626 \mathrm{e} 10$ & \\
$\mathrm{E}_{2}(\mathrm{~Pa})$ & & & \\
& & & \\
In-plane shear modulus & $5 \mathrm{e} 9$ & $4.9 \mathrm{e} 9$ & \\
$\mathrm{G}_{12}(\mathrm{~Pa})$ & & & 0.42 \\
& 0.28 & 0.32 & 7500 \\
\hline In-plane Poisson's ratio $\mathrm{v}_{12}$ & 1404 & 1536 & \\
\hline
\end{tabular}

Table 2 The numbers of element and layer with the maximum principal

\begin{tabular}{lcc}
\multicolumn{3}{c}{ stress $(\mathrm{J}=1.08)$} \\
\hline $\begin{array}{c}\text { The number of } \\
\text { element }\end{array}$ & $\begin{array}{c}\text { The number of } \\
\text { layer }\end{array}$ \\
\hline 4381 composite propeller & 20 & 1 \\
4382 composite propeller & 400 & 5 \\
4383 composite propeller & 1 & 17 \\
4384 composite propeller & 1 & 17 \\
\hline
\end{tabular}

